\title{
High Temperature Metamaterial Enhanced Electromagnetic Absorbing Coating Prepared With Alumina Ceramic
}

Shixin Zhao ( $\nabla$ zhaosin1518@126.com )

Department of Basic Sciences, Air Force Engineering University, Xi'an, 710051, China https://orcid.org/0000-0002-9974-8160

Hua Ma

Air Force Engineering University

Tengqiang Shao

Air Force Engineering University

Jun Wang

Air Force Engineering University

Zhaoning Yang

Xi'an University of Posts and Telecommunications

Yueyu Meng

Air Force Engineering University

Mingde Feng

Air Force Engineering University

Jiafu Wang

Air Force Engineering University

Yanmin Jia

Xi'an University of Posts and Telecommunications

Shaobo Qu

Air Force Engineering University

\section{Research Article}

Keywords: EM absorbing coatings, high temperature, metamaterial, alumina ceramic

Posted Date: January 13th, 2021

DOI: https://doi.org/10.21203/rs.3.rs-143546/v1

License: (a) (i) This work is licensed under a Creative Commons Attribution 4.0 International License.

Read Full License 
Version of Record: A version of this preprint was published at Journal of Alloys and Compounds on September 1st, 2021. See the published version at https://doi.org/10.1016/j.jallcom.2021.159822. 


\title{
High Temperature Metamaterial Enhanced Electromagnetic Absorbing
}

\section{Coating Prepared with Alumina Ceramic}

\author{
Shinxin Zhao ${ }^{\mathrm{a}}$, Hua Ma ${ }^{\mathrm{a}, *}$, Tengqiang Shao ${ }^{\mathrm{a}}$, Jun Wang ${ }^{\mathrm{a}, * *}$, Zhaoning Yang ${ }^{\mathrm{b}}$, \\ Yueyu Meng ${ }^{\mathrm{a}}$, Mingde Feng ${ }^{\mathrm{a}}$, Jiafu Wang ${ }^{\mathrm{a}}$, Yanmin Jia ${ }^{\mathrm{b}}$, Shaobo $\mathrm{Qu}^{\mathrm{a}}$
}

a Department of Basic Sciences, Air Force Engineering University, Xi'an, 710051, China

b School of Science, Xi' an University of Posts and Telecommunications, Xi' an, 710121, China

\begin{abstract}
At present, a series of challenges are impeding the large-scale application of the high temperature radar absorbing coatings (RACs), such as the complex preparation of raw material and the complicated technology of processing. In this paper, a new, thin and high-temperature metamaterial RAC (MRAC) with strong absorption was designed and experimentally demonstrated, composing of a radar absorbing coating and a layer of metamaterial. To avoid the need for the complex preparation of raw materials, pure alumina was selected as the radar absorbing coating. Meanwhile, plasma spraying and screen printing were employed to simplify the manufacture technology to produce the absorbing coating and the metamaterial layer, ensuring its feasibility and practicality. The metamaterial layer was prepared with a high temperature conductive paste and it improved the impedance matching of the coating and regulated the electromagnetic (EM) resonance. With the ability to consume more incident EM waves, excellent absorption performance at high temperature was achieved with relatively small thickness. In the $8 \sim 18 \mathrm{GHz}$ band, the MRAC bandwidth for reflection loss $(R L)$ below $-5 \mathrm{~dB}$ almost covered the frequency of $10 \sim 18 \mathrm{GHz}$ with a thickness of only $1.5 \mathrm{~mm}$ at $800{ }^{\circ} \mathrm{C}$. This new metamaterial has broad application prospects by the virtue of its simplicity and ease of production.
\end{abstract}

Keywords: EM absorbing coatings; high temperature; metamaterial; alumina ceramic

\footnotetext{
${ }^{*}$ Corresponding author.

${ }^{* *}$ Corresponding author.

E-mail address: mahuar@xjtu.edu.cn (H. Ma); wangjun563@163.com (J. Wang).
} 


\section{Introduction}

With the rapid development of advanced radar detection and precision guidance capability, stealth performance has become an important performance factor and a significant feature of modern and future combat weapons and equipment ${ }^{[1-3]}$. As an effective means of stealth and camouflage, radar absorbing materials (RAMs) have become one of the most important military high-tech materials. The ideal RAMs should be light weight and thin, and have strong absorption ability and a wide band ${ }^{[4-9]}$. Moreover, its chemical composition should be stable enough to withstand different environments. RAMs can be divided into coating type and structural type according to their material forming process and bearing capacity ${ }^{[10]}$. Radar absorbing coatings (RACs) are a kind of coating material which consists of a base material resin (binder), absorbents, fillers and auxiliary agents. The coatings are always coated on the external surface of the target. The radar absorbing structures (RASs) are usually structural composite materials that are formed by dispersing the absorbents in the structural materials which are reinforced by special fibers (such as glass fiber), and they have dual functions of carrying and absorbing electromagnetic waves (EM). RACs are suitable for various curved surfaces with complex shapes that have good heat resistance and strong mechanical properties. With coating technology, there is no need to greatly modify the structure and shape of objects in order to enhance their stealth performance [11-14]. Therefore, RACs can be suitably applied over existing equipment. Meanwhile, some high temperature components that require stealth at high temperatures up to $700{ }^{\circ} \mathrm{C}$ are directly exposed to radar waves and will strongly reflect radar waves under those working conditions, increasing the detection probability by radar ${ }^{[15-22]}$. Hence, many scientists have become interested in the development of RACs that are resistant to high temperatures. 
In recent years, numerous materials have been used in the design, preparation and research of RACs, including metal oxides, ceramics, and carbon-based materials, such as $\mathrm{Si}_{3} \mathrm{~N}_{4}, \mathrm{SiC}_{\mathrm{f}} / \mathrm{SiC}, \mathrm{TiC}, \mathrm{Ti}_{3} \mathrm{SiC}_{2}, \mathrm{ZnO}, \mathrm{MnO}_{2}$, carbon fibers, CNTs and graphene ${ }^{[23-39]}$. Nonetheless, there are still many issues, such as high thickness, complex preparation and processing technology, which limit the large-scale application of RACs at hightemperatures. Therefore, there is important application value in the design of novel high-temperature RACs.

Metamaterials are artificial materials with supernormal physical properties, and they have been a popular research topic in recent years. By arranging the artificial unit structure in a specific way, an artificial structure material (metamaterials) with special electromagnetic properties can be formed. They possess unique properties that the original natural materials do not have, such as negative refractive index, negative permeability, negative dielectric constant and so on ${ }^{[40-42]}$. In recent years, a series of RAMs based on metamaterials have been studied and they have shown impressive results $^{[43-48]}$. However, most of the conductive and dielectric materials used in metamaterials that have been studied are room-temperature materials, such as FR4, polyimide, aluminum and copper, which cannot be used in high-temperature environments. Therefore, to achieve high-temperature microwave absorption, it is necessary to find high-temperature conductive and dielectric materials.

In this study, we designed a new high-temperature metamaterial RAC (MRAC) focused on the $8 \sim 18 \mathrm{GHz}$ band and produced it using atmospheric plasma spraying and screen printing. The high temperature ceramic alumina, $\left(\mathrm{Al}_{2} \mathrm{O}_{3}\right)$, was selected as the dielectric. $\mathrm{Al}_{2} \mathrm{O}_{3}$ is already widely used in ceramic coatings due to its excellent mechanical and thermal properties. Furthermore, using pure alumina instead of composite materials as the dielectric material eliminates the complexity of RAC 
preparation. By optimizing the metamaterial structure, MRACs can excite relatively strong magnetic responses, even if they do not contain magnetic materials, which create strong electromagnetic wave absorption. The impedance mismatch of the coating can be effectively improved as well, to allow more electromagnetic waves to penetrate into the coating and be consumed. Eventually, in the $8 \sim 18 \mathrm{GHz}$ band and with a thickness of $1.5 \mathrm{~mm}$, the bandwidths of reflection loss $(R L)$ below $-5 \mathrm{~dB}$ and $-10 \mathrm{~dB}$ reached 5.75 $\mathrm{GHz}$ and $1.92 \mathrm{GHz}$, respectively, at $800^{\circ} \mathrm{C}$. This study provides an effective solution to reduce the thickness of the RAC and improve its impedance matching at high temperatures. It is worth noting that the RAC is easy to produce and has great potential for applications.

\section{Design and experiment}

\subsection{Design principle}

In high temperature applications, many components (such as the components in an aircraft engine) have very strict requirements for the thickness of the RACs, and coatings that are too thick are not acceptable. However, thin RACs usually cannot achieve the desired absorption properties. Therefore, in order to enhance the microwave absorption performance of thin coatings, a type of periodic metamaterial structural unit coated on the surface of alumina coating was designed using high-temperature conductive paste, as shown in Fig.1. The absorption properties of the RAC were enhanced by the periodic metamaterial structural unit in two ways. First, through the appropriate design, the metamaterial layer excited a relatively strong magnetic response, even though magnetic materials were not incorporated at high temperatures. Second, the metamaterial structure improved the impedance matching of the coating, which allowed more EM to enter the coating and be consumed. The introduction of metamaterials greatly reduced the thickness of RAC and improved its absorption performance. 


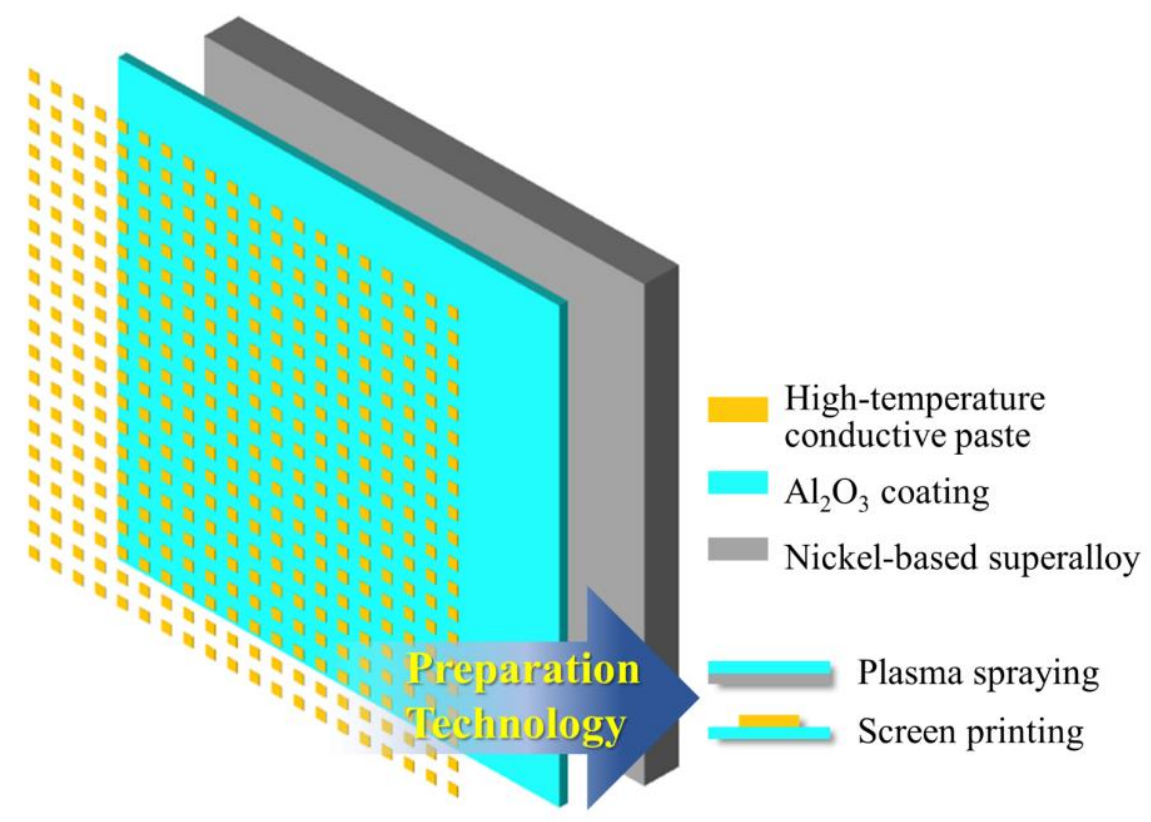

Fig. 1. The design schematic of the proposed MRAC.

\subsection{Samples production and property characterization}

The advantages of plasma spraying technology are that the process is simple, costs are low, and it is a suitable application method to use on objects of various shapes. Therefore, plasma spraying technology was selected to be used in the preparation of the $\mathrm{Al}_{2} \mathrm{O}_{3}$ coating. In this study, high-purity $\mathrm{Al}_{2} \mathrm{O}_{3}$ powders were selected as the raw material, and they were purchased from Beijing Sanhao Technology Development Co., Ltd., China.

The high temperature conductive paste was prepared by mixing conductive materials $\left(\mathrm{Pt}, \mathrm{MoSi}_{2}, \mathrm{TiB}_{2}\right)$ and glass powder evenly and then fully grinding them together with an organic carrier. The metamaterial layer was fabricated by 200 -mesh screen printing, which allowed the high temperature conductive paste to penetrate on the surface of the $\mathrm{Al}_{2} \mathrm{O}_{3}$ coating. To fasten the conductive paste in place and form a conductive passages, the sample was dried and sintered at $850^{\circ} \mathrm{C}$.

The phase structure of the $\mathrm{Al}_{2} \mathrm{O}_{3}$ coating, derived by the plasma spraying process, was examined by an X-ray diffractometer (Philips X-Pert ProDiffractometer, Almelo, 
The Netherlands). The microstructure of the coating was observed through a scanning electron microscope (SEM, model JSM-6360, JEOL, Tokyo, Japan). The $\mathrm{Al}_{2} \mathrm{O}_{3}$ coating was processed into the dimensions $22.86 \times 10.16 \times 1.5 \mathrm{~mm}$ and its EM parameters were measured through an Agilent Technologies E8362B PNA network analyzer with the waveguide in $\mathrm{X}$ band at $800{ }^{\circ} \mathrm{C}$. The measured electromagnetic scattering parameters (S parameters) were converted into permittivity through mathematical calculations. Finally, the reflection loss $(R L)$ of a $180 \mathrm{~mm} \times 180 \mathrm{~mm}$ MRAC prototype was tested with an arch reflection test system at $800{ }^{\circ} \mathrm{C}$. It should be noted that the temperature was kept at $800{ }^{\circ} \mathrm{C}$ for $15 \mathrm{~min}$ to improve the accuracy of testing at high temperatures.

\section{Results and discussions}

Fig. 2(a) shows the processing of the $\mathrm{Al}_{2} \mathrm{O}_{3}$ coating, which was easily coated on the surface of the super alloy. The $\mathrm{XRD}$ results of the $\mathrm{Al}_{2} \mathrm{O}_{3}$ coating at $800{ }^{\circ} \mathrm{C}$ are shown in Fig. 2(b). A typical $\mathrm{Al}_{2} \mathrm{O}_{3}$ phase was clearly observed which indicated that $\mathrm{Al}_{2} \mathrm{O}_{3}$ maintained excellent chemical stability at high temperatures.

(a)

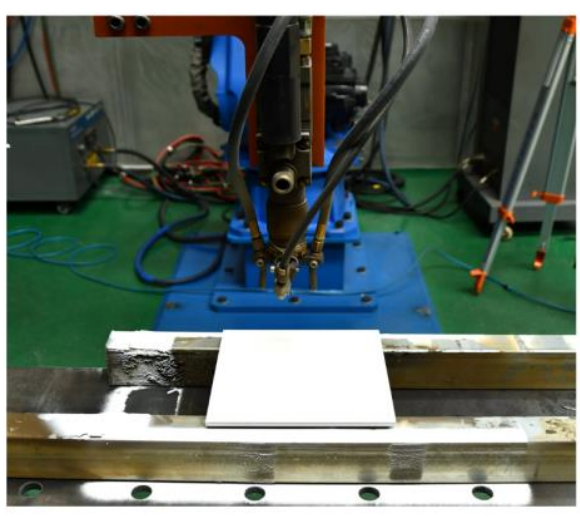

Plasma spraying (b)

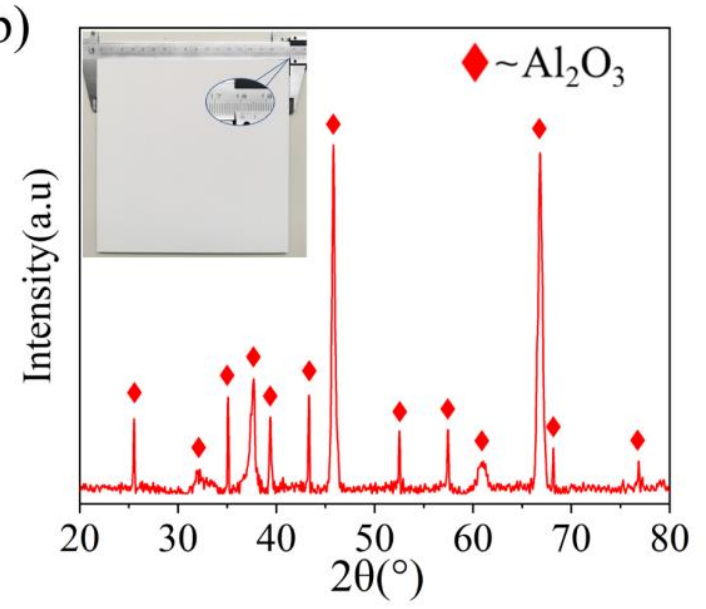

Fig. 2. (a) The $\mathrm{Al}_{2} \mathrm{O}_{3}$ coating process; (b) The XRD pattern of the $\mathrm{Al}_{2} \mathrm{O}_{3}$ coating at $800{ }^{\circ} \mathrm{C}$.

Figs. 3(a-b) show the microstructures of the $\mathrm{Al}_{2} \mathrm{O}_{3}$ feedstock powders observed with scanning electron microscopy. The powders were prepared by the sintering and crushing method, which is one of the most effective methods to prepare plasma 
spraying powder. The prepared powders generally had some rough angular shape and the interior of the particle was relatively dense. The diameter of the prepared powders varied from $30 \mu \mathrm{m}$ to $60 \mu \mathrm{m}$, which ensured excellent fluidity and made the feedstock powders suitable for plasma spraying. Figs. 3(c-d) show the magnified sectional SEM images of the $\mathrm{Al}_{2} \mathrm{O}_{3}$ coating. It can be observed that the coating had a high density and there were no visible pores. Additionally, the grains were clearly lamellar and evenly distributed, which are the typical features of coatings produced through plasma spraying.

As shown in Fig. 4(a), the metamaterial structure was fabricated through screen printing. Since $\mathrm{Al}_{2} \mathrm{O}_{3}$ is a non-magnetic material, the real and the imaginary part of the coating permeability were 1 and 0 , respectively. The real part $\left(\varepsilon^{\prime}\right)$ and the imaginary part $\left(\varepsilon^{\prime \prime}\right)$ of permittivity of the coating at $800^{\circ} \mathrm{C}$ is shown in Fig. 3(b), which was calculated by the experimental values of the S-parameter (a function of frequency). The theoretical basis of the calculation was based on the transmission line
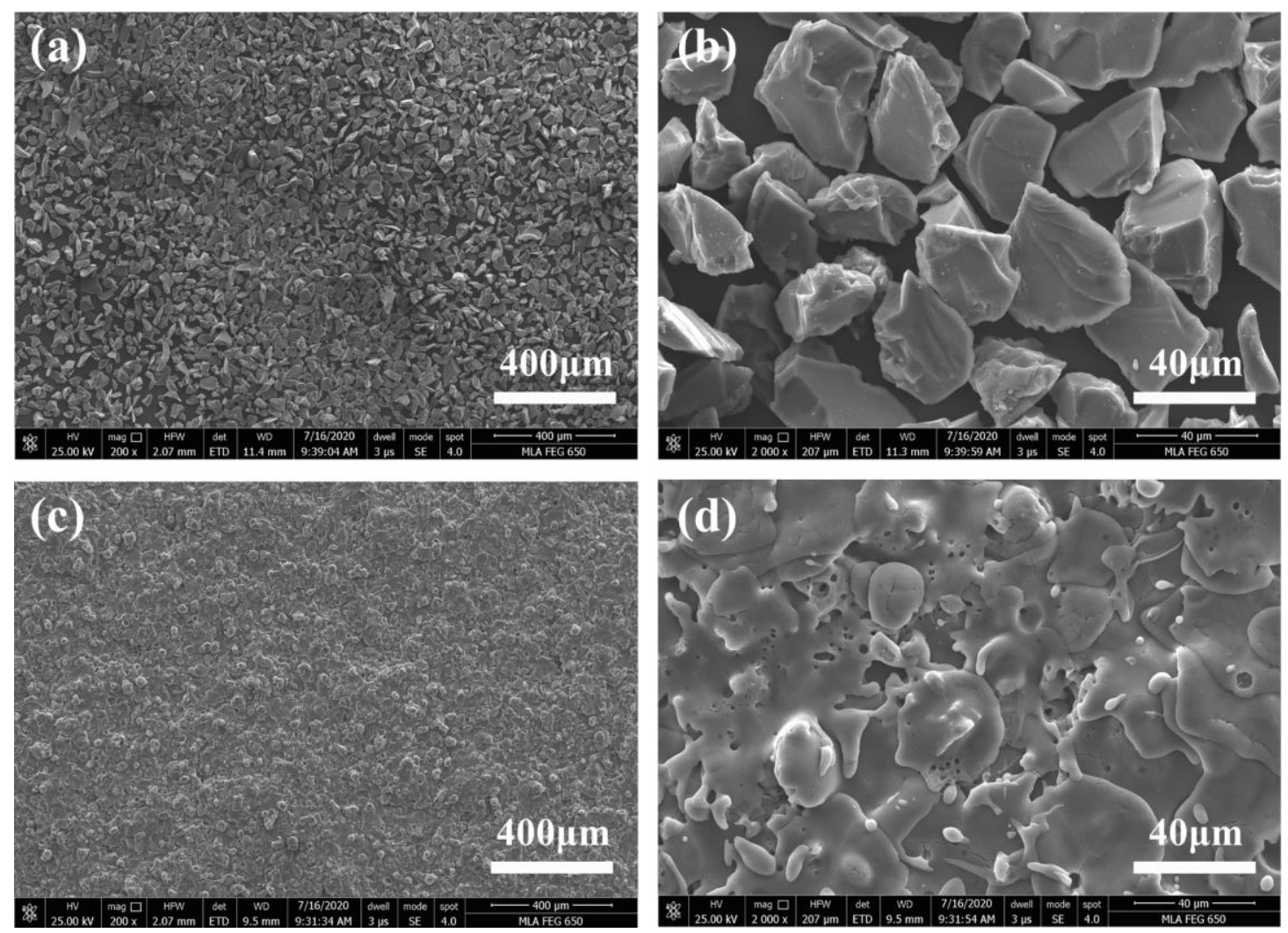
Figs. 3. (a),(b) Morphology of feedstock powders; (c), (d) Cross sectional SEM of the $\mathrm{Al}_{2} \mathrm{O}_{3}$ coating.

theory ${ }^{[49]}$, as shown in the following formulas:

$$
\begin{gathered}
\mu=n z \\
\varepsilon=n / z \\
Z= \pm \sqrt{\frac{\left(1+S_{11}\right)^{2}-S_{21}^{2}}{\left(1-S_{11}\right)^{2}-S_{21}^{2}}} \\
X=1 / 2 S_{21}\left(1-S_{11}^{2}+S_{21}^{2}\right) \\
e^{i n k_{0} d}=X \pm i \sqrt{1-X^{2}}
\end{gathered}
$$

where $\varepsilon$ represented the permittivity and $\mu$ the permeability; $Z$ represented the impedance and $n$ the effective refractive index; $K_{0}$ was the wave number of the incident wave and $d$ the thickness of the sample. From Eqs. (1) to (6), the corresponding EM parameters of the material were calculated based on the measured S parameters. From the calculated results (Fig. 4(b)), it was clearly observed that the real and imaginary parts of the permittivity of the $\mathrm{Al}_{2} \mathrm{O}_{3}$ coating experienced little change in the $\mathrm{X}$-band, therefore, $\mathrm{Al}_{2} \mathrm{O}_{3}$ can be regarded as a weak frequency dispersive material. In simulations, the permittivity in the $8 \sim 18 \mathrm{GHz}$ band was obtained by fitting the measured results and the corresponding quarter-wavelength was further calculated between 8 18GHz. As the frequency changed from $8 \mathrm{GHz}$ to $18 \mathrm{GHz}$, the $\lambda / 4$ value varied from $3.27 \mathrm{~mm}$ to $1.51 \mathrm{~mm}$, which represented the optimal EM matching thickness. In addition, through the following equations, the $R L$ of the $\mathrm{Al}_{2} \mathrm{O}_{3}$ coating at different thicknesses was obtained, and the results are shown in Fig. 4(c).

$$
\begin{gathered}
R L=20 \lg |R| \\
Z_{\text {in }}=\sqrt{\frac{\mu}{\varepsilon}} \tanh \left(j \frac{2 \pi f d}{c} \sqrt{\mu \varepsilon}\right) \\
R=\frac{Z_{\text {in }}-1}{Z_{\text {in }}+1}
\end{gathered}
$$


Where $\mathrm{R}$ represented the complex reflection coefficient, $Z_{\text {in }}$ the normalized input impedance. $c$ the speed of light in vacuum and $d$ the coating thickness. $\mu$ and $\varepsilon$ represented the permeability and permittivity of the materials, respectively. Here, $\varepsilon$ is shown in Fig. 4(b) and the real and the imaginary parts of $\mu$ was equal to 1 and 0 for this nonmagnetic coating, however, all RLs were above -10 dB. Regardless, the coating was too thick to be practically applied in this case. Therefore, we designed a metamaterial layer to enhance the absorption property of the coating and reduce its thickness. As shown in Fig. 4(d), the conductivity $(\sigma)$ of the high temperature conductive paste was measured as the temperature changed. It was observed that $\sigma$ decreased rapidly as the temperature increased towards $200^{\circ} \mathrm{C}$, then the rate of descent gradually slowed down afterwards. When the temperature reached $800^{\circ} \mathrm{C}, \sigma$ decreased to $1.56^{*} 10^{5} \mathrm{~S} / \mathrm{m}$, which was sufficient to meet the electrical conductivity requirements of the metamaterial layer.

(a)

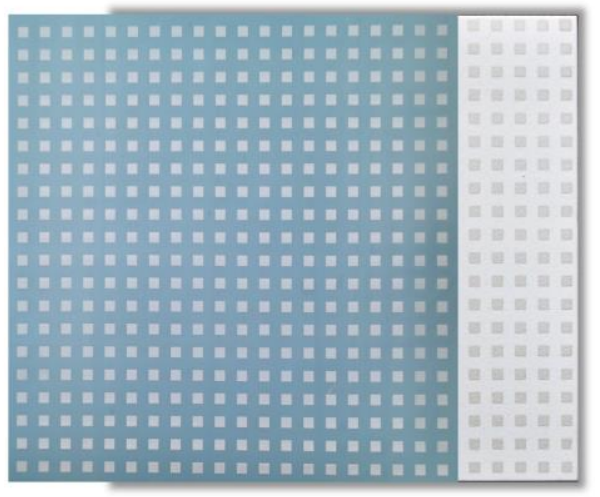

(c)

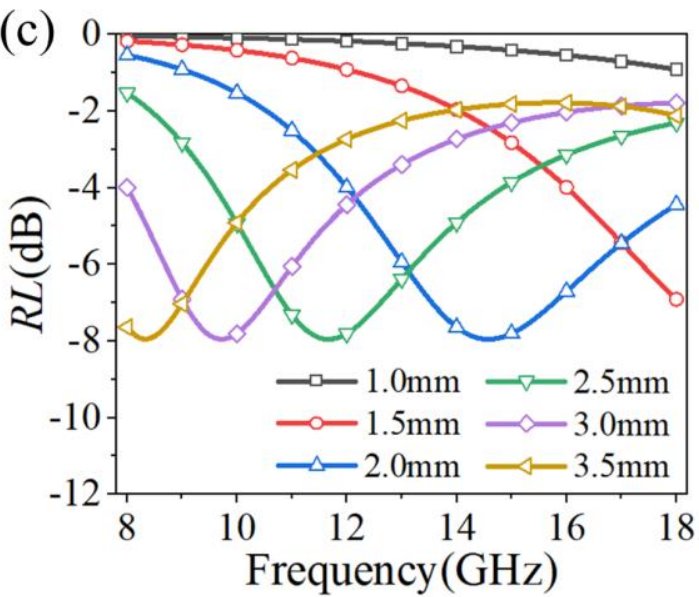

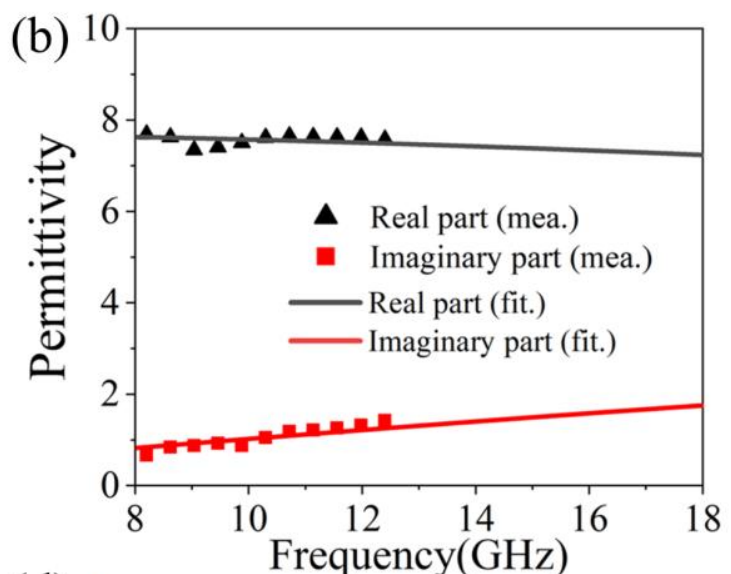

(d)

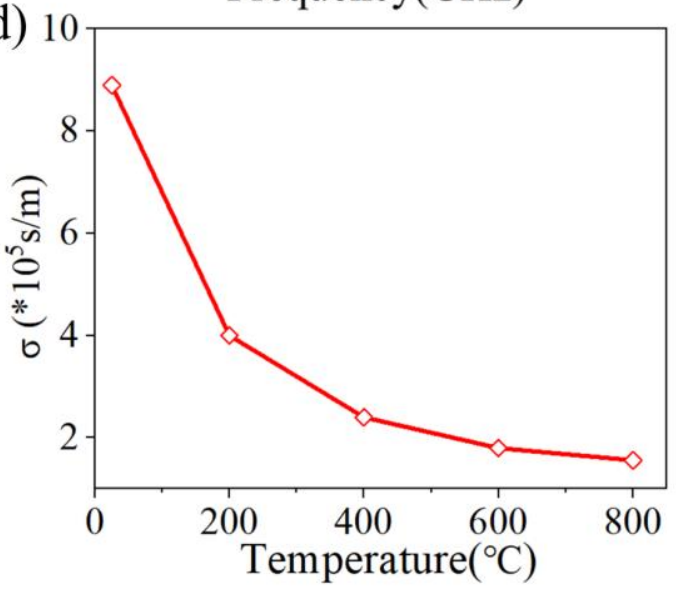


Fig. 4. (a) Screen printing to fabricate the initial-state prototype; (b) Measured and fitted permittivity of the $\mathrm{Al}_{2} \mathrm{O}_{3}$ coating; (c) The $\mathrm{RL}$ of the single $\mathrm{Al}_{2} \mathrm{O}_{3}$ coating with different thicknesses at $800{ }^{\circ} \mathrm{C}$; (d) The $\sigma$ of the high temperature conductive paste at various temperatures.

Fig. 5(a) shows the schematic diagram of the front and lateral views of the MRAC. The bottom gray layer represents the nickle-based superalloy with thickness of $t_{0}$, the bottom blue layer represents the $\mathrm{Al}_{2} \mathrm{O}_{3}$ coating with thickness of $t_{1}$, the top yellow layer represents the metamaterial layer with thickness of $t_{2}$ and the side length of the periodic structure unit was $a$. From the figure, it can be seen that the metamaterial unit cell was a small square with side length of $b$. To achieve optimal performance, the above parameters were optimized in the CST. The $x$ and $y$ directions represented the boundary of the periodic structure unit to simulate an infinite surface structure. In addition, the $z$ direction was deemed as an open boundary and the excited incident EM wave came vertically from the $Z_{\max }$ port. In order to optimize the parameters, the $R L$ target was set as far below $-5 \mathrm{~dB}$ as possible. Through the optimization algorithm, a series of optimized dimensions were obtained, namely, $t_{l}=1.5 \mathrm{~mm}, a=9 \mathrm{~mm}$ and $b=4 \mathrm{~mm}$.
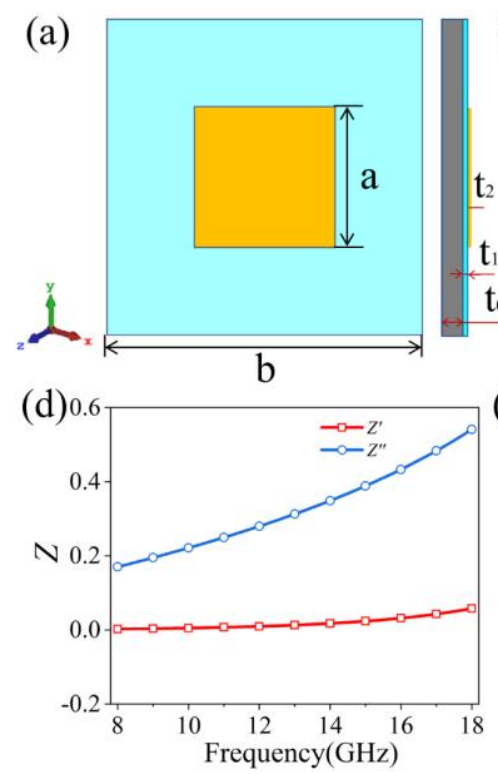

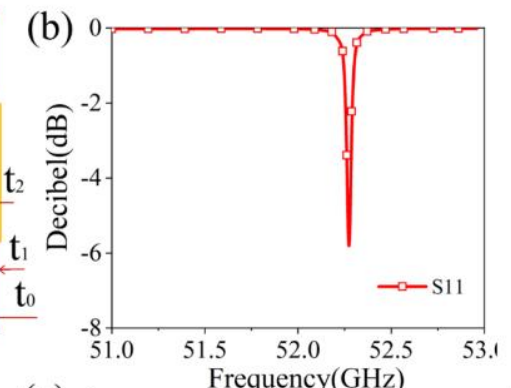

(e)

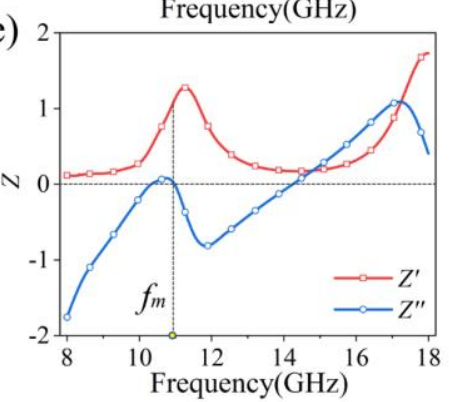

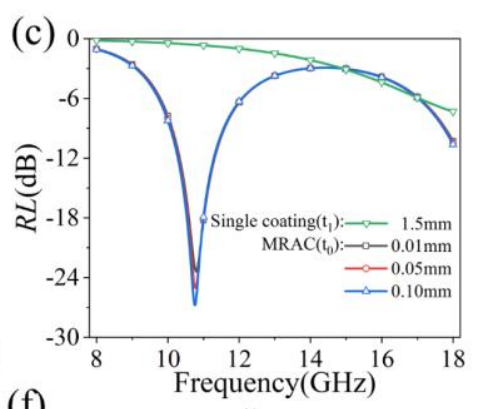

(f)

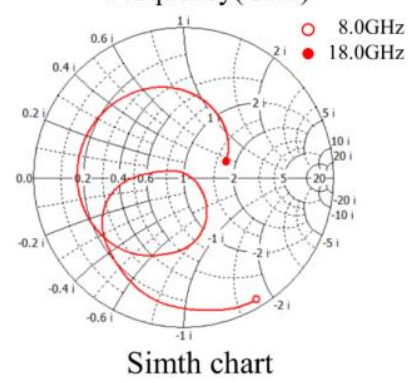

Fig. 5. (a) The front and lateral view of the MRAC unit structure; (b) The S parameter of the single metamaterial structure at various $f$; (c) The simulated $R L$ of the single $\mathrm{Al}_{2} \mathrm{O}_{3}$ coating and the MRAC 
with different $\mathrm{t}_{2} \mathrm{~S}$ at $800{ }^{\circ} \mathrm{C}$; (d) $\mathrm{Z}$ of the single $\mathrm{Al}_{2} \mathrm{O}_{3}$ coating with a thickness of $1.5 \mathrm{~mm}$; (e) $\mathrm{Z}$ of the MRAC; (d) The smith chart.

Fig. 5(b) indicates a high resonant frequency (around $52.3 \mathrm{GHz}$ ) from the metamaterial structure alone. The resonant peak can be tuned to the $8 \sim 18 \mathrm{GHz}$ band via coupling with a coating of specific relative permittivity. Under the combined effect of electric loss from the metamaterial and dielectric loss from the $\mathrm{Al}_{2} \mathrm{O}_{3}$ coating, a large amount of EM waves at a certain resonant frequency were consumed and converted to thermal energy. Furthermore, the influence of $t_{2}$ on the optimal wave absorption performance was investigated, as shown in Fig. 5(c). When the thickness $\left(t_{2}\right)$ of the metamaterial layer increased from $0.001 \mathrm{~mm}$ to $0.1 \mathrm{~mm}$, the absorption peak only changed slightly from 22.7 to $26.8 \mathrm{~dB}$. This small change in absorption intensity indicated that the stable absorption performance of the MRAC can be acquired regardless of the small changes in the coating thickness. This result also proved the feasibility of using the screen printing to prepare the metamaterial layer. As a comparison, the absorption performance of a single $\mathrm{Al}_{2} \mathrm{O}_{3}$ coating is shown in Fig. 6 , and it can be concluded that the MRAC was obviously superior to the coating alone, which strongly proved the effectiveness of the proposed metamaterial coating.

To further investigate the absorption enhanced mechanism of the metamaterial, the normalized impedance of the $\mathrm{Al}_{2} \mathrm{O}_{3}$ coating alone and the composite MRAC were calculated as shown in Figs. 5(d-e), and the calculated smith chart is also shown in Fig. 5(f). Obviously, it can be observed from Fig. 5 (d) that the real part of the $Z$ (single coating) was basically close to 0 and the imaginary part increased as frequency increased, indicating that the EM impendence was visibly mismatched with the space free impendence. Thus, almost no EM waves were absorbed. As shown in Fig. 5 (e), $Z^{\prime}$ reached the maximum value and $Z^{\prime \prime}$ was equal to 0 at the optimal absorption frequency 
$\left(f_{m}\right)$, indicating that the best absorption performance occurred at this point. In addition, compared with the single $\mathrm{Al}_{2} \mathrm{O}_{3}$ coating, the $Z^{\prime}$ value of the MRAC improved significantly but the $Z^{\prime \prime}$ value decreased, which indicated that the metamaterial layer significantly improved the impedance mismatch condition. Therefore, more EM waves can enter the MRAC and be consumed.

Additional information about the absorption mechanism of this high temperature MRAC was provided by its surface current field distribution upon the incident EM waves at the absorption peak frequency $(10.87 \mathrm{GHz})$. Compared to its working wavelength $(27.5 \mathrm{~mm})$, the thickness of MRAC $(1.5 \mathrm{~mm})$ was much lower. The simulation results showed that there arose an obvious near-field coupling at the absorption peak frequency between the metamaterial coating's surface and the bottom metal plate.

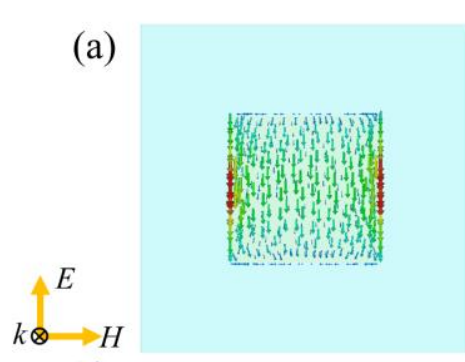

(d)

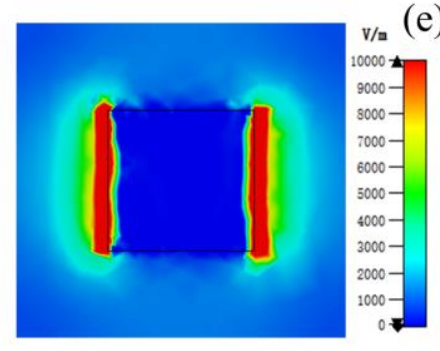

(b)

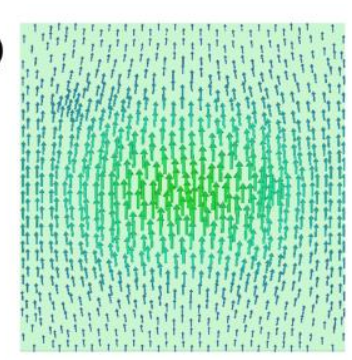
(e) (c)

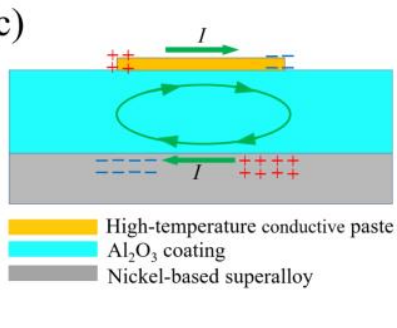

(f)

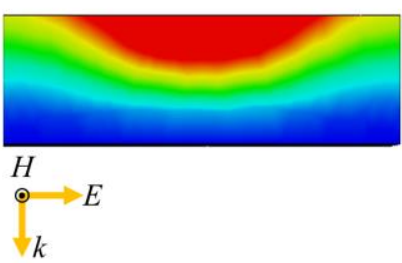

Fig. 6. (a) The surface current in the metamaterial structure unit; (b) The reflective metal back plate current distribution; (c) Schematic of charge distribution for the MRAC and the circulating current; (d) The surface electric field of the MRAC; (e) The surface energy loss of MRAC; (f) The energy loss of a section. 
As shown in Figs. 6(a-b), surface electric currents in opposite directions were induced simultaneously on the metamaterial structure unit surface and the metal plate underneath. Meanwhile, the generated alternative currents then induced alternative magnetic fields, as indicated by the green arrows in Fig. 6(c), inducing a significant increase in the surface electric currents. The surface power loss was markedly improved by the enhanced surface current. To further research the loss distribution of this high temperature MRAC, the surface electric field at the absorption peak frequency in the $\mathrm{x}$ o-y plane was also monitored. As shown in Fig. 6(d), it was obvious that the magnetic resonance circuit augmented a significant electric field enhancement on the surface of the metamaterial coating. Moreover, the following formula can explain the absorption of EM energy by a loss medium:

$$
P_{a b s}=1 / 2\left(\omega \varepsilon^{\prime \prime}+\sigma\right) \times|E|^{2}
$$

Where, $\omega$ represented the angular frequency, $\varepsilon$ " was the imaginary part of permittivity, and $E$ represented the total electric field strength. The equation indicated that as $\varepsilon^{\prime \prime}$ and $E$ increased, EM absorption performance will also rise correspondingly. As seen from Fig. 6(e), the energy loss of the incident EM wave increased obviously in the electric field enhancement area. Thus, an excellent level of absorption was obtained at that certain frequency. Furthermore, in Fig. 6(f) the EM energy loss shown in the section diagram of the metamaterial unit indicated that the resonance also affected the $\mathrm{Al}_{2} \mathrm{O}_{3}$ coating, and the degree of influence decreased gradually from the metamaterial layer to the bottom.

Through simulations, the RCS reduction results of the monolayer $\mathrm{Al}_{2} \mathrm{O}_{3}$ coating at a thickness of $1.5 \mathrm{~mm}$ and $800^{\circ} \mathrm{C}$ were obtained, as shown in Fig. 7. The results show that the RCS of the monolayer $\mathrm{Al}_{2} \mathrm{O}_{3}$ coating changed slightly compared to the pure 
metal. However, the RCS of the MRAC was much lower, which proved that the design of the metamaterial coating greatly enhanced RCS reduction.

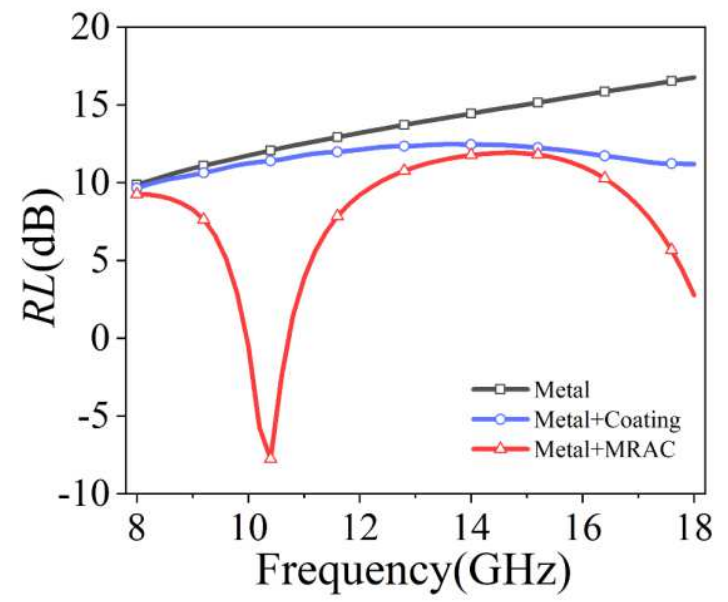

Fig. 7. The simulated high temperature RCS spectra of the single $\mathrm{Al}_{2} \mathrm{O}_{3}$ coating and the MRAC.

To visually investigate RCS reduction of the MRAC, three-dimensional scattering patterns were simulated for the MRAC, the single $\mathrm{Al}_{2} \mathrm{O}_{3}$ coating and the metal plate in the absorption peak frequency $(10.87 \mathrm{GHz})$ at $800^{\circ} \mathrm{C}$, as shown in Fig. 8. Figs. 8(a-c) show that the RCS of MRAC scattering decreased significantly compared with the metal plate in the direction of the main lobe. However, the RCS of the single $\mathrm{Al}_{2} \mathrm{O}_{3}$ coating did not change at all. Furthermore, as shown in Figs. 8(d-f), the RCS of MRAC reduced significantly in all directions compared with the single coating, especially in the main lobe. 

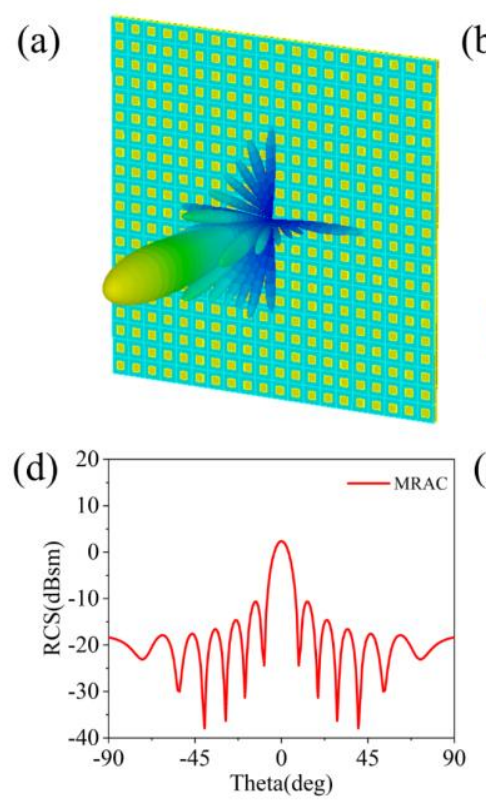
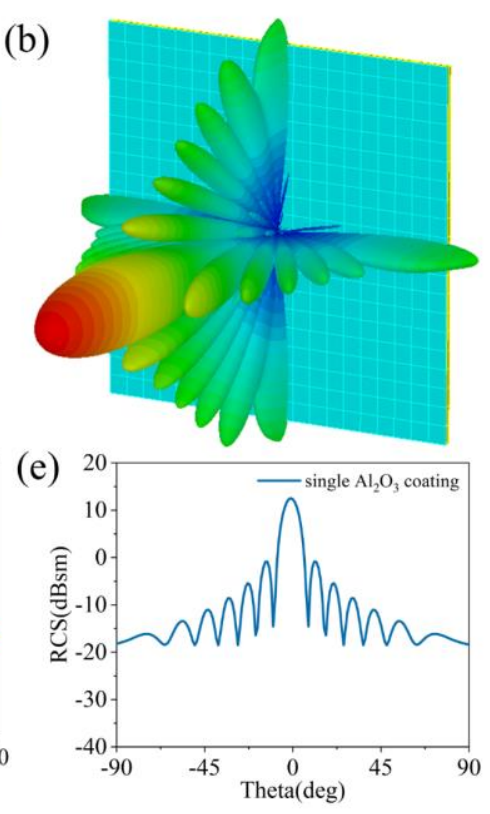
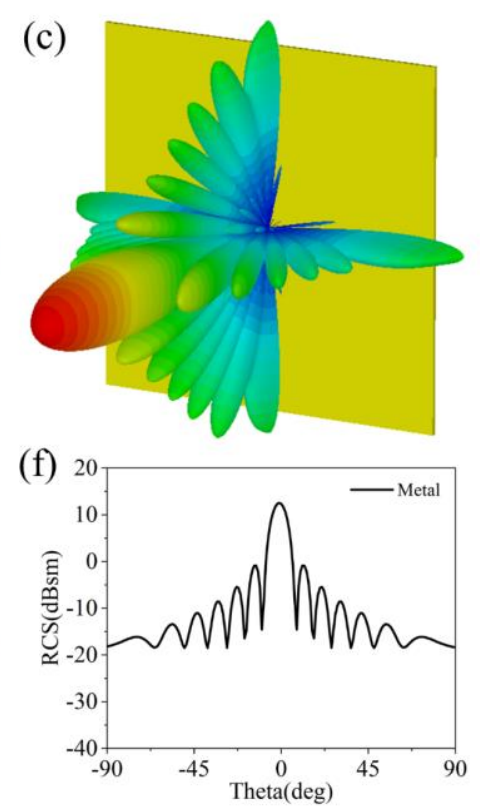

Fig. 8. (a)(b)(c) The far field three-dimensional scattering patterns of MRAC, the single coating and the metal plate, respectively; (d)(e)(f) Their RCS in planes of Phi $=0^{\circ}$.

To examine the theoretical EM absorption performance at high temperatures, a prototype MRAC was produced through plasma spraying and screen printing, as shown in Fig. 9(a). The samples were heated gradually to $800{ }^{\circ} \mathrm{C}$ and kept at those conditions for 15 min, as shown in Fig. 9(b). Then, a temperature test system was used to measure and calculate the $R L$ of the MRAC prototype in an anechoic chamber covered with a certain wave absorbing wedge material. The test system consisted of a pair of horn antennas (one transmitted EM waves and the other received), a high temperature heating plate, and a vector network analyzer. Fig. 9(b) shows the comparison between the actual measured results and the simulation calculated results. It was observed that the measured results were basically consistent with the simulated values. In addition, the absorption peak frequency of the test results was $11.56 \mathrm{GHz}$ and the lowest reflectivity was $-11.2 \mathrm{~dB}$, which was a small difference compared with the simulated results. The error can be ascribed to the machining thickness error of the $\mathrm{Al}_{2} \mathrm{O}_{3}$ coating 
and the size error of the metamaterial structural unit. Also, the bandwidths of $R L$ below $-5 \mathrm{~dB}$ almost covered the frequency of $10 \sim 18 \mathrm{GHz}$ with a thickness of only $1.5 \mathrm{~mm}$.

(a)

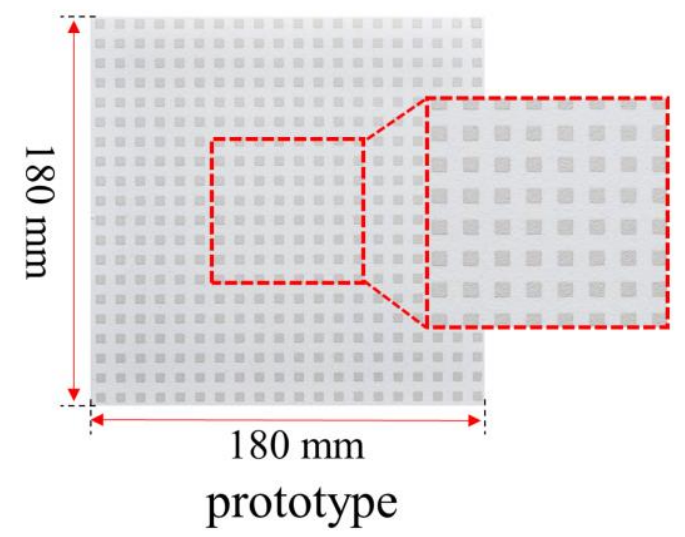

(b)

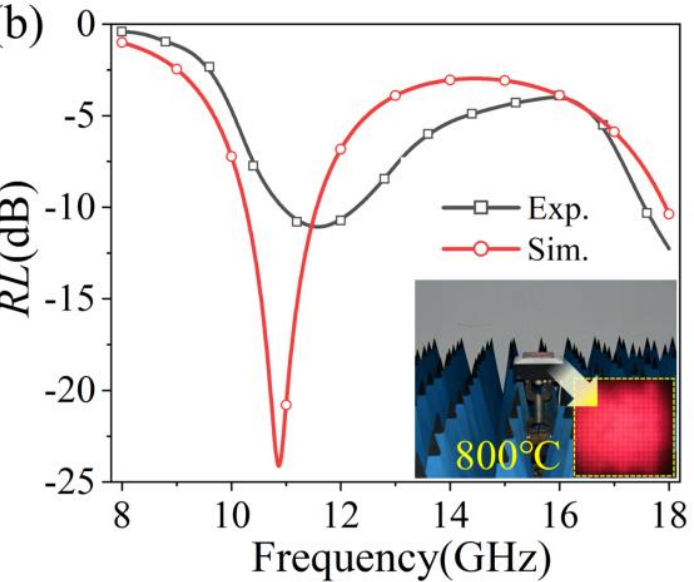

Fig. 9. (a) The produced prototype of the MRAC; (b) A comparison between the experimental and simulated results.

\section{Conclusion}

In this study, in order to achieve a high temperature metamaterial with broadband EM wave absorption using simple processing technology, we have designed and fabricated a high temperature MRAC with excellent performance based on metamaterials and alumina. The prototype was produced through plasma spraying and screen printing, and the phase structure and microstructure of the coating were also observed. The main conception was to optimize the impedance matching and improve the incident EM waves energy dissipation of the coating through metamaterial design. Through simulations, we observed the appearance of obvious near-field coupling at the absorption peak frequency between the surface and bottom of the MRAC, which eventually led to the consumption of a large amount of incident EM wave energy. To verify the effectiveness of this design, a prototype was manufactured and tested at high temperatures. Allowing for all reasonable errors, the measured values were basically 
consistent with the simulation results, which strongly proved that our designed MRAC possessed excellent EM wave absorption performance in the $8 \sim 18 \mathrm{GHz}$ band at $800^{\circ} \mathrm{C}$ with a thickness of $1.5 \mathrm{~mm}$. Compared with the previous high temperature absorbing materials, the MRAC we designed does not require complex raw material processing technology. This simplicity and ease of production creates a wide range of applications for this new MRAC.

\section{Funding}

The authors are grateful to the support from the National Natural Science Foundation of China (Grants 61671467 and 61671466) and the National key R\&D program of china (Grant 2017YFA0700201).

\section{Declaration of competing interest}

The authors declare that they have no known competing financial interests or personal relationships that could have appeared to influence the work reported in this paper.

\section{Credit authorship contribution statement}

Shixin Zhao: Writing - original draft, Formal analysis. Hua Ma: Writing - original draft, Formal analysis. Tengqiang Shao: Writing - original draft, Formal analysis. Jun Wang: Writing - original draft, Formal analysis. Zhaoning Yang: Formal analysis. Yueyu Meng : Formal analysis. Mingde Feng: Formal analysis. Jiafu Wang: Formal analysis. Yanmin Jia: Formal analysis. Shaobo Qu: Formal analysis. 


\section{References}

[1] W. Q. Wang, Moving-target tracking by cognitive RF stealth radar using frequency diverse array antenna, IEEE Trans. Geosci. Electron. 54 (2016) 3764-3773.

[2] M.S. Pinho, M.L. Gregori, C.R. Nunes, B.G. Soares, Performance of radar absorbing materials by waveguide measurements for $\mathrm{X}$-and $\mathrm{Ku}$-band frequencies, $\mathrm{J}$. Eur. Polym. 38 (2002) 2321-2327.

[3] K. Zikidis, A. Skondras, C. Tokas, Low observable principles, stealth aircraft and anti-stealth Technologies, Stealth Aircraft and Anti-Stealth Technol. 4 (2014) $129 \mathrm{e} 165$

[4] L. Zhou, W. Zhou, J. Su, F. Luo, D. Zhu, Y. Dong, Plasma sprayed $\mathrm{Al}_{2} \mathrm{O}_{3} / \mathrm{FeCrAl}$ composite coatings for EM wave absorption application, Appl. Surf. Sci. 258 (2012) 2691e2696.

[5] L. Liu, K. Zhou, P. He, T. Chen, Synthesis and microwave absorption properties of carbon coil-carbon fiber hybrid materials, Mater. Lett. 110 (2013) 76e79.

[6] L. Kong, Z. Li, L. Liu, R. Huang, M. Abshinova, Z. Yang, C. Tang, P. Tan, C. Deng, S. Matitsine, Recent progress in some composite materials and structures for specific EM applications, Int. Mater. Rev. 58 (2013) 203e259.

[7] B. Wen, M. Cao, M. Lu, W. Cao, H. Shi, J. Liu, X. Wang, H. Jin, X. Fang, W. Wang, J. Yuan, Reduced graphene oxides: light-weight and high-efficiency EM interference shielding at elevated temperatures, Adv. Mater. 26 (2014) 3484e3489.

[8] F.B. Meng, H.G. Wang, F. Huang, Y.F. Guo, Z.Y. Wang, D. Hui, Z.W. Zhou, Graphene-based microwave absorbing composites: a review and prospective, Composites Part B 137 (2018) 260e277. 
[9] D. Zhao, F. Luo, W. Zhou, D. Zhu, Effect of critical plasma spray parameter on complex permittivity and microstructure by plasma spraying $\mathrm{Cr} / \mathrm{Al}_{2} \mathrm{O}_{3}$ coatings, Appl. Surf. Sci. 264 (2013) 545e551.

[10] A. Kumar, S. Singh, Development of coatings for radar absorbing materials at X-band, IOP Conf. Ser. Mater. Sci. Eng. 330 (2018), 012006.

[11] Z. Yang, F. Luo, J. Xu, W. Zhou, D. Zhu, Dielectric and microwave absorption properties of $\mathrm{LaSrMnO} 3 / \mathrm{A} 12 \mathrm{O} 3$ ceramic coatings fabricated by atmospheric plasma spraying, J. Alloy. Comp. 662 (2016) $607 \mathrm{e} 611$.

[12] S. K. Singh, M. J. Akhtar, K. K. Kar, Impact of $\mathrm{Al}_{2} \mathrm{O}_{3}, \mathrm{TiO}_{2}, \mathrm{ZnO}$ and $\mathrm{BaTiO}_{3}$ on the microwave absorption properties of exfoliated graphite/epoxy composites at $\mathrm{X}$ band frequencies, Composites Part B 167 (2019) 135-146.

[13] S. K. Singh, M. J. Akhtar, K. K. Kar, Hierarchical Carbon Nanotube-Coated Carbon Fiber: Ultra Lightweight, Thin, and Highly Efficient Microwave Absorber, ACS Appl. Mater. Interfaces 10 (2018) 24816-24828.

[14] S. K. Singh, M. J. Akhtar, and K. K. Kar, Synthesis of a Lightweight Nanocomposite Based on Polyaniline 3D Hollow Spheres Integrated Milled Carbon Fibers for Efficient X-Band Microwave Absorption, Ind. Eng. Chem. Res. 59 (2020) 9076-9084.

[15] R.C. Che, L.M. Peng, X.F. Duan, Q. Chen, X.L. Liang, Microwave absorption enhancement and complex permittivity and permeability of Fe encapsulated within carbon nanotubes, Adv. Mater. 16 (2004) 401-405.

[16] J.B. Kim, S.K. Lee, C.G. Kim, Comparison study on the effect of carbon nano materials for single-layer microwave absorbers in X-band, Compos. Sci. Technol. 68 (2008) 2909-2916. 
[17] Y. Zhang, Y. Huang, T. Zhang, H. Chang, P. Xiao, H. Chen, Z. Huang, Y. Chen, Broadband and tunable high-performance microwave absorption of an ultralight and highly compressible graphene foam, Adv. Mater. 27 (2015) 2049-2053.

[18] Q.L. Wen, W.C. Zhou, J.B. Su, Y.C. Qing, F. Luo, D.M. Zhu, Dielectric and micro-wave absorption properties of plasma sprayed short carbon fibers/glass composite coatings, J. Mater. Sci.: Mater. Electron. 27 (2015) 1783-1790.

[19] X. Tang, K. Hu, Preparation and electromagnetic wave absorption properties of Fe-doped zinc oxide coated barium ferrite composites, Mater. Sci. Eng. B 139 (2007) $119-123$.

[20] H.Y. Wang, D.M. Zhu, W.C. Zhou, F. Luo, High temperature electromagnetic and microwave absorbing properties of polyimide/multi-walled carbon nanotubes nanocomposites, Chem. Phys. Lett. 633 (2015) 223-228.

[21] H.Y. Wang, D.M. Zhu, W.C. Zhou, F. Luo, Electromagnetic and microwave absorbing properties of polyimide nanocomposites at elevated temperature, J. Alloys Compd. 648 (2015) 313-319.

[22] M.M. Lu, X.X. Wang, W.Q. Cao, J. Yuan, M.S. Cao, Carbon nanotube/CdS core-shell nanowires with tunable and high-efficiency microwave absorption at elevated temperature, Nanotechnology 27 (2016) 065702.

[23] Z.R Jia, K.J Lin, G.L Wu, X. Hui, H.J Wu, M.S. Cao, Recent Progresses of High-Temperature Microwave-Absorbing Materials, Nano: brief reports and reviews $13(2018) 1830005$.

[24] Q. Zhou, X.W. Yin, F. Ye, Z.M. Tang, R. Mo, L.F. Chen, High temperature electro-magnetic wave absorption properties of $\mathrm{SiC}_{\mathrm{f}} / \mathrm{Si} \mathrm{N} 4$ composite induced by different SiC fibers, Ceram. Int. 45 (2019) 6514-6522. 
[25] M. Li, X.W. Yin, G.P. Zheng, M. Chen, M.J. Tao, L.F. Cheng, L.T. Zhang, High-temperature dielectric and microwave absorption properties of $\mathrm{Si}_{3} \mathrm{~N}_{4}-\mathrm{SiC}_{2} \mathrm{SiO}_{2}$ composite ceramics, J. Mater. Sci. 50 (2015) 1478-1487.

[26] S.K. Singh, M.J. Akhtar, K.K. Kar, Impact of $\mathrm{Al}_{2} \mathrm{O}_{3}$, $\mathrm{TiO}_{2}, \mathrm{ZnO}$ and $\mathrm{BaTiO}_{3}$ on the microwave absorption properties of exfoliated graphite/epoxy composites at Xband frequencies, Compos. Part B 167 (2019) 135-146.

[27] F. Ye, L.T. Zhang, X.W. Yin, Y.J. Zhang, L. Kong, Q. Li, Y.S. Liu, L.F. Cheng, Dielectric and EMW absorbing properties of PDCs-SiBCN annealed at different temperatures, J. Eur. Ceram. Soc. 33 (2013) 1469-1477.

[28] Y.C. Qing, Y. Mu, Y.Y. Zhou, F. Luo, D.M. Zhu, W.C. Zhou, Multiwalled carbon nanotubes- $\mathrm{BaTiO}_{3} /$ silica composites with high complex permittivity and improved electromagnetic interference shielding at elevated temperature, J. Eur. Ceram. Soc. 34 (2014) 2229-2237.

[29] F. Ye, L.T. Zhang, X.W. Yin, Y.J. Zhang, L. Kong, Q. Li, Y.S. Liu, L.F. Cheng, Dielectric and microwave-absorption properties of $\mathrm{SiC}$ nanoparticle/SiBCN composite ceramics, J. Eur. Ceram. Soc. 34 (2014) 205-215.

[30] M.H. Li, X.W. Yin, H.L. Xu, X.L. Li, L.F. Cheng, L.T. Zhang, Interface evolution of a $\mathrm{C} / \mathrm{ZnO}$ absorption agent annealed at elevated temperature for tunable electro-magnetic properties, J. Eur. Ceram. Soc. 00 (2019) 1-11.

[31] H. Gao, F. Luo, H.W. Deng, H.Y. Nan, Y.C. Qing, Fabrication of SiCf/SiCmullite composite with improved pretreatment condition via precursor infiltrationsintering combined with infiltration-pyrolysis process, Ceram. Int. 45 (2019) 1606216069. 
[32] H.H. Song, W.C. Zhou, F. Luo, Z.B. Huang, Y.C. Qing, Y. Mu, Temperature dependence of dielectric properties of $\mathrm{SiC}_{\mathrm{f}} / \mathrm{PyC} / \mathrm{SiC}$ composites, Mater. Sci. Eng. B 195 (2015) 12-19.

[33] Y. Mu, W.C. Zhou, Y. Hu, H.Y. Wang, F. Luo, D.H. Ding, Y.C. Qing, Temperature-dependent dielectric and microwave absorption properties of $\mathrm{SiC}_{\mathrm{f}} / \mathrm{SiC}$ $\mathrm{Al}_{2} \mathrm{O}_{3}$ composites modified by thermal cross-linking procedure, J. Eur. Ceram. Soc. 35 (2015) 2991-3003.

[34] Y. Liu, F. Luo, J.B. Su, W.C. Zhou, D.M. Zhu, Enhanced mechanical, dielectric, and microwave absorption properties of $\mathrm{ZnO} / \mathrm{ZrSiO}_{4}$ composite ceramics by adding $\mathrm{Al}_{2} \mathrm{O}_{3}$ powders, Phys. Status Solidi A 211 (2014) 2574-2579.

[35] C. Chen, L.M. Pan, S.C. Jiang, S. Yin, X.Y. Li, J.X. Zhang, Y.B. Feng, J. Yang, Electrical conductivity, dielectric and microwave absorption properties of grapheme nanosheets/magnesia composites, J. Eur. Ceram. Soc. 8 (2018) 1639-1646.

[36] M.M. Lu, W.Q. Cao, H.L. Shi, X.Y. Fang, J. Yang, Z.L. Hou, H.B. Jin, W.Z. Wang, J. Yuan, M.S. Cao, Multi-wall carbon nanotubes decorated with ZnO nanocrystals: mild solution-process synthesis and highly efficient microwave absorption proper-ties at elevated temperature, J. Mater. Chem A (2014) 10540.

[37] C.J. Luo, T. Jiao, J.W. Gu, Y.S. Tang, J. Kong, Graphene shield by SiBCN ceramic: a promising high-temperature electromagnetic wave-absorbing material with oxidation resistance, ACS Appl. Mater. Interfaces 10 (2018) 39307-39318.

[38] J.B. Su, W.C. Zhou, Y. Liu, F. Luo, D.M. Zhu, Atmosphere plasma-sprayed carbon nanotubes/cordierite nanocomposite coatings for microwave absorption applications, J. Therm. Spray Technol. 23 (2014) 1065-1072.

[39] L. Liu, K. Zhou, P. He, T. Chen, Synthesis and microwave absorption properties of carbon coil-carbon fiber hybrid materials, Mater. Lett. 110 (2013) 76-79. 
[40] H. Tao, W.J. Padilla, X. Zhang, et al., Recent progress in electromagnetic metamaterial devices for terahertz applications, IEEE J. Sel. Top. Quant. Electron. 17 (1) (2011) 92e101.

[41] J.B. Pendry, A.J. Holden, D.J. Robbins, et al., Magnetism from conductors and enhanced nonlinear phenomena, IEEE Trans. Microw. Theor. Tech. 47 (1999) $2075 \mathrm{e} 2084$.

[42] R.A. Shelby, D.R. Smith, S. Schultz, Experimental verification of a negative index of Refraction, Science 292 (2001) 77e79.

[43] X. Qiao, X. Chen, Z. Wu, Z.L. Zhang, Z.L. Wang, L.Y. Heng, S. Wang, Y. Zou, T.Z. Xiang, An ultra-broadband and lightweight fishnet-like absorber in microwave region, J. Phys. Appl. Phys. 51 (28) (2018), 285002.

[44] Y.Z. Chen, B. He, J.C. Zhao, R.Z. Gong, Ultra-thin low-frequency broadband microwave absorber based on magnetic medium and metamaterial, J. Electron. Mater. 46 (2017) 1293e1299.

[45] Y.X. Huang, W.L. Song, C.X. Wang, Y.N. Xu, W.Y. Wei, M.J. Chen, L.Q. Tang, D. N. Fang, Multi-scale design of electromagnetic composite metamaterials for broadband microwave absorption, Compos. Sci. Technol. 162 (2018) 206e214.

[46] Y.Z. Chen, Z.Z. Chen, X.S. Mao, R.Z. Gong, Ultra-thin multi-band polarization-insensitive microwave metamaterial absorber based on multiple-order responses using a single resonator structure, Materials 10 (11) (2017) 1241.

[47] W.S. Yuan, Y.Z. Chen, Low-frequency and broadband metamaterial absorber based on lumped elements: design, characterization and experiment, Appl. Phys. A 117 (2014) $1915 \mathrm{e} 1921$. 
[48] Y.Z. Chen, Y. Zao, H. Luo, F. Chen, X.S. Mao, Compact ultra-thin sevenband microwave metamaterial absorber based on a single resonator structure, J. Electron. Mater. 48 (2019) 3939e3946.

[49] G.B. Shan, Y.Z. Chen, Y.J. Li, C.Y. Zhang, H. Dong, Y.B. Dong, W.X. Zhang, L. K. Huang, T. Suo, F. Liu, High temperature creep resistance of a thermally stable nanocrystalline Fe-5 at.\% Zr steel, Scripta, Materials 179 (2010) 1e5. 


\section{Figures}

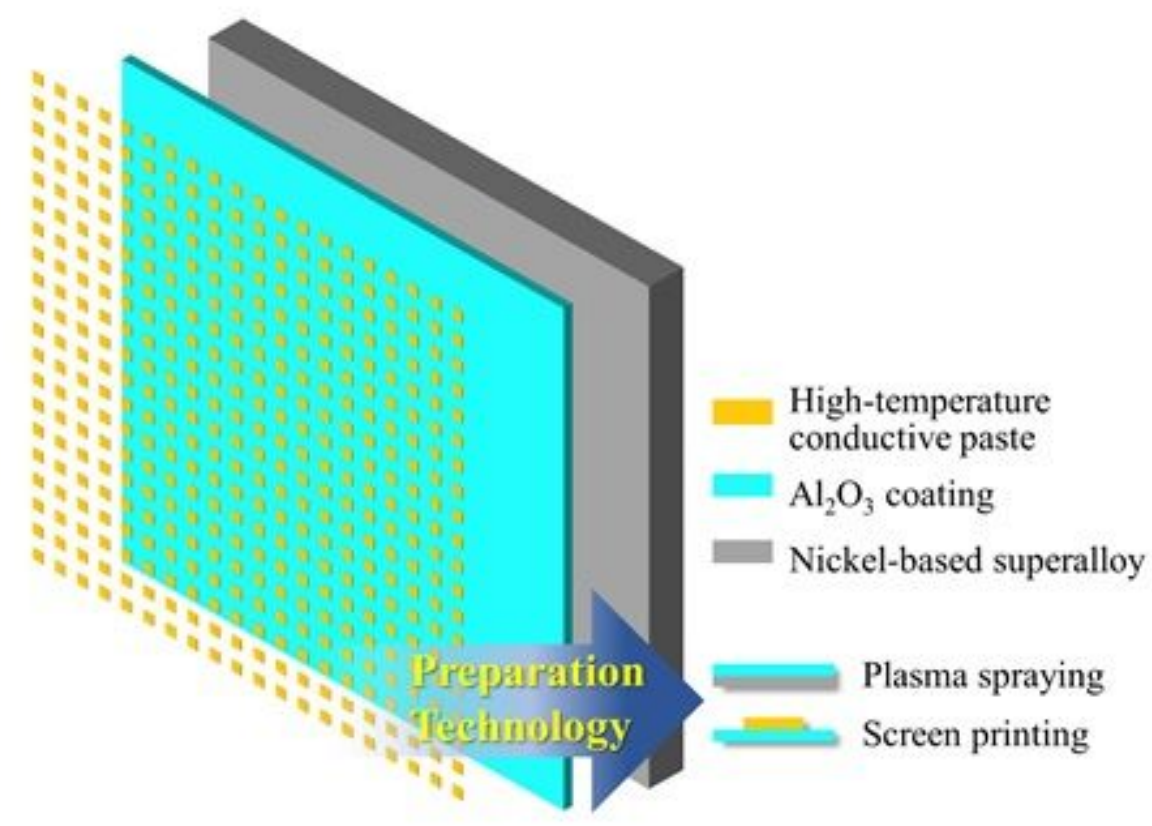

Figure 1

The design schematic of the proposed MRAC.

(a)

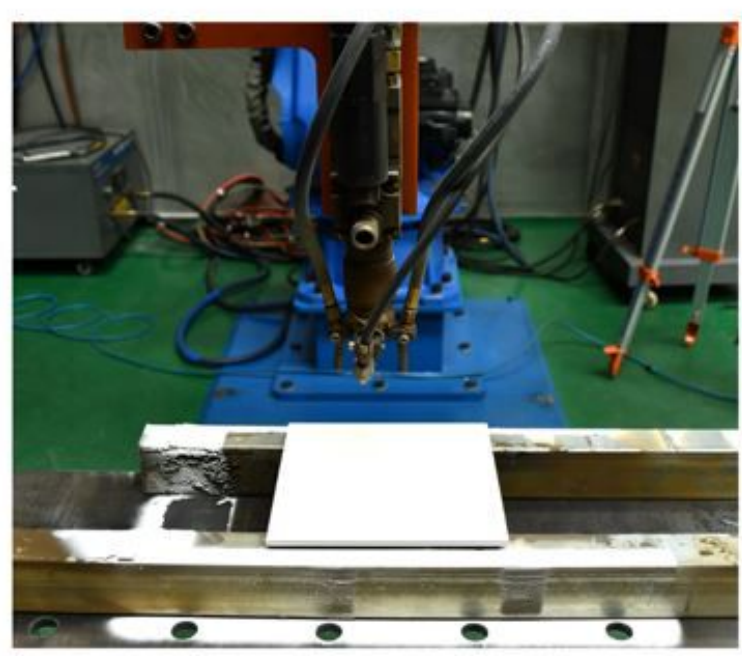

Plasma spraying (b)

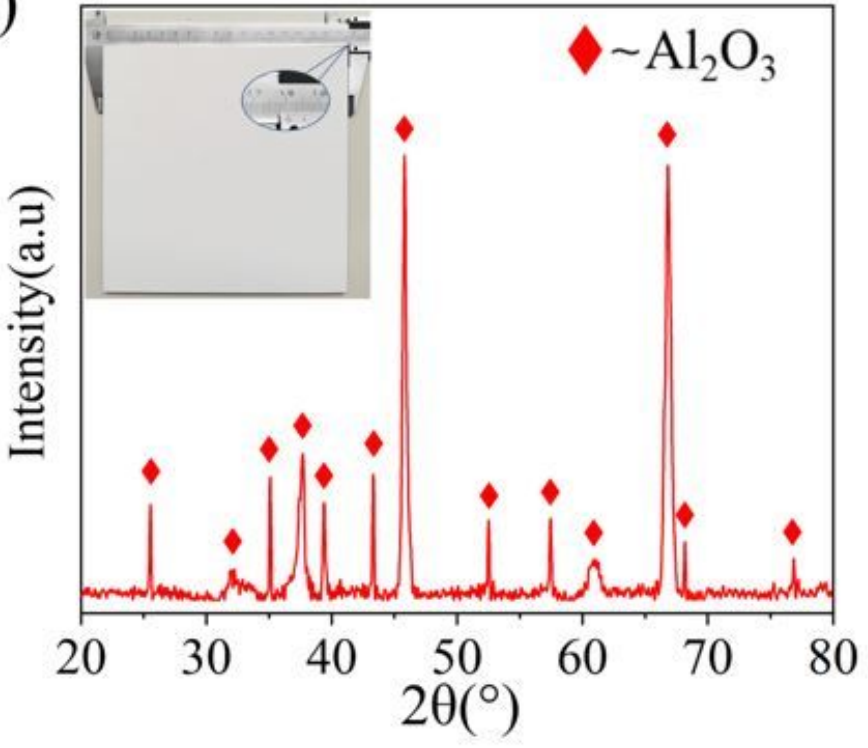

Figure 2

(a) The Al2O3 coating process; (b) The XRD pattern of the Al2O3 coating at $800 \rrbracket$. 

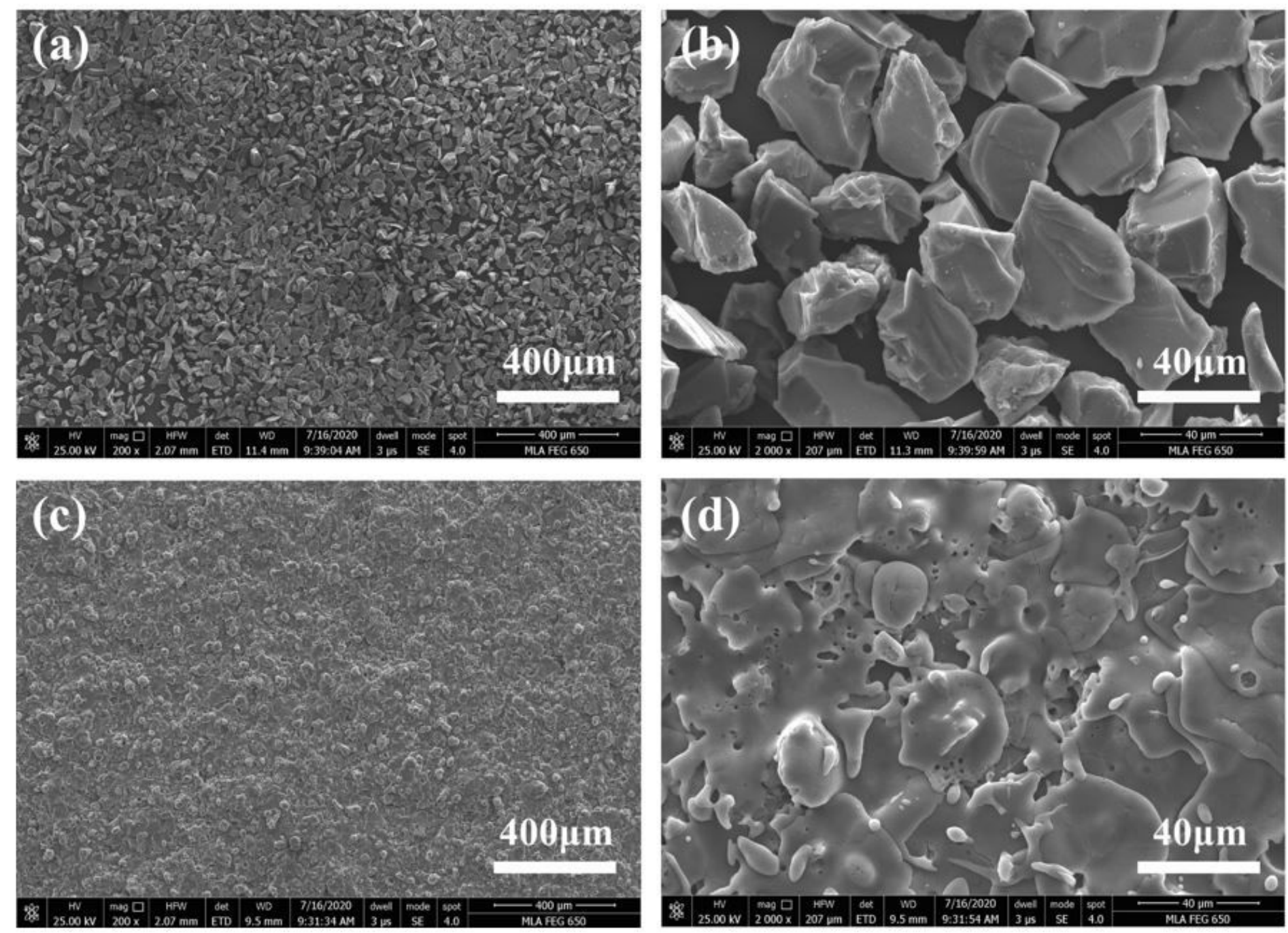

Figure 3

(a),(b) Morphology of feedstock powders; (c), (d) Cross sectional SEM of the Al2O3 coating. 

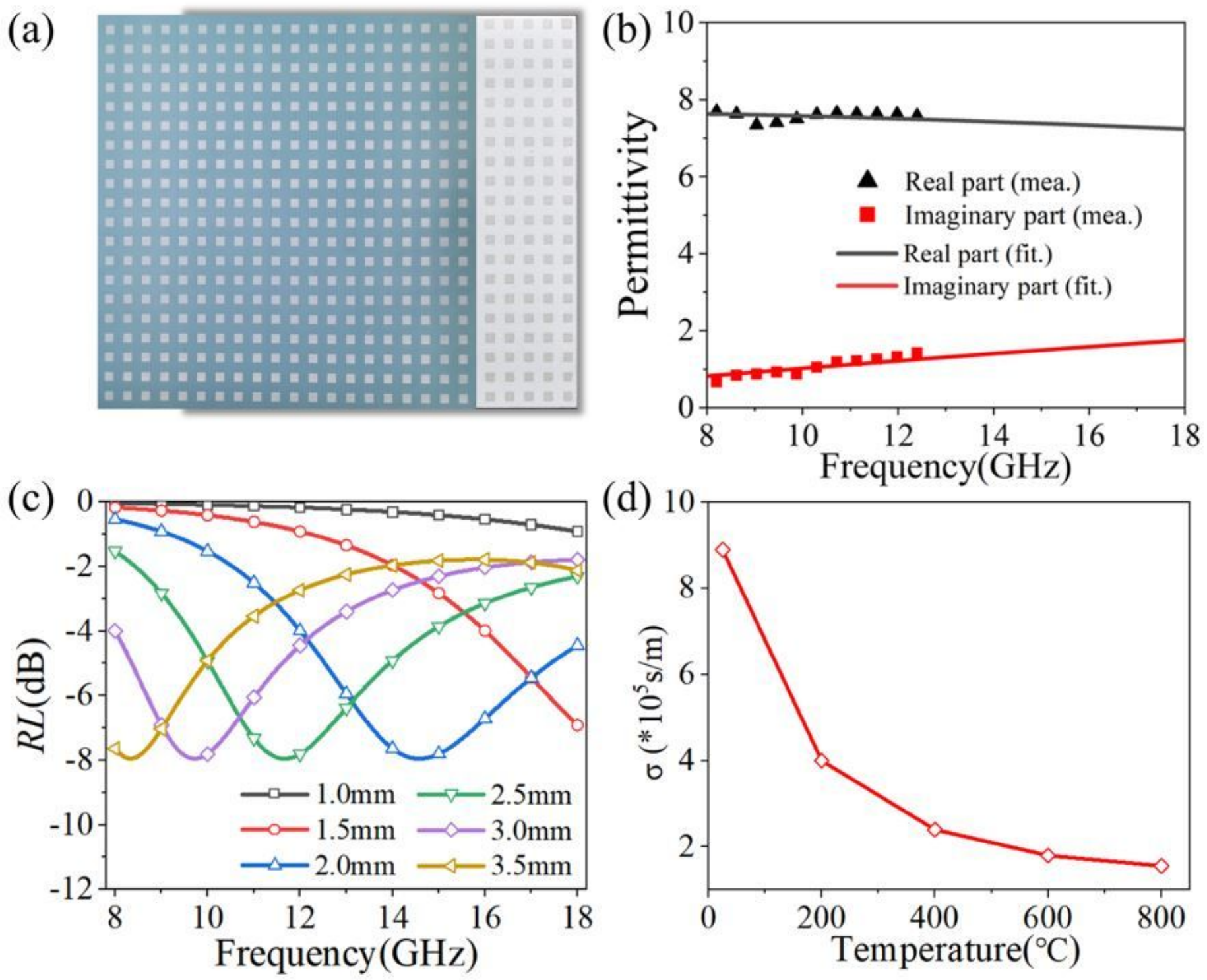

\section{Figure 4}

(a) Screen printing to fabricate the initial-state prototype; (b) Measured and fitted permittivity of the Al2O3 coating; (c) The RL of the single Al203 coating with different thicknesses at $800 \otimes ;$ (d) The $\sigma$ of the high temperature conductive paste at various temperatures. 

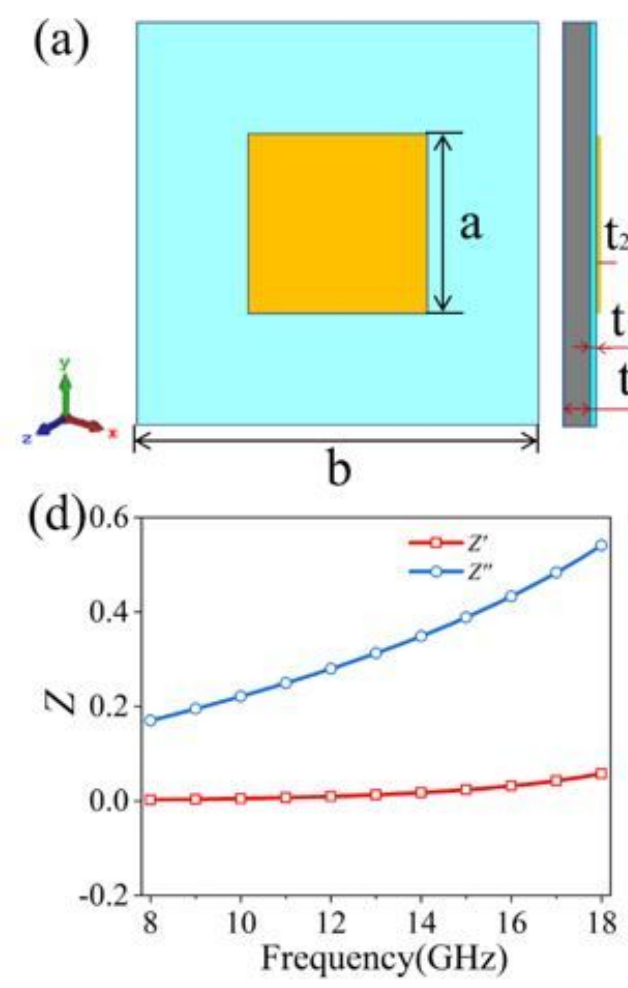

(b)

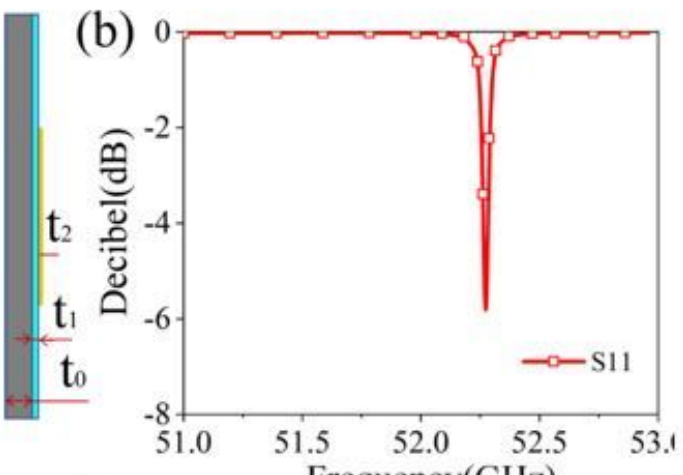

(e)

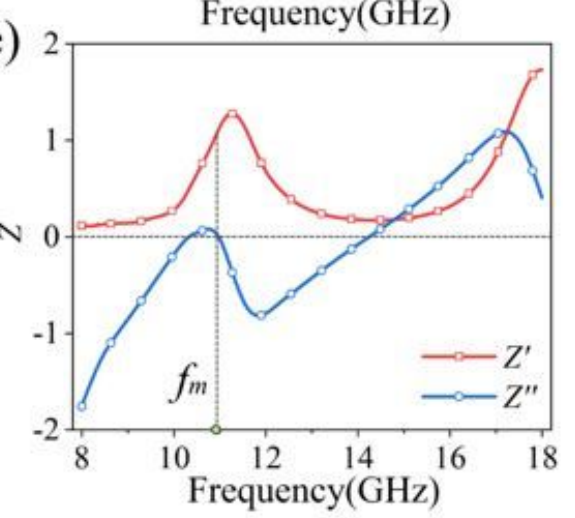

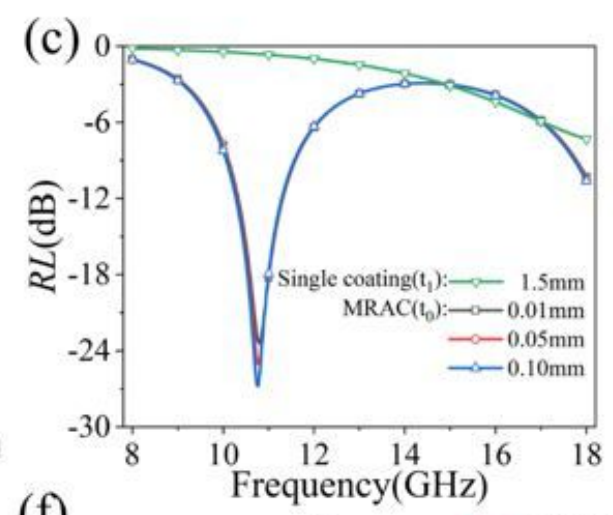

(f)

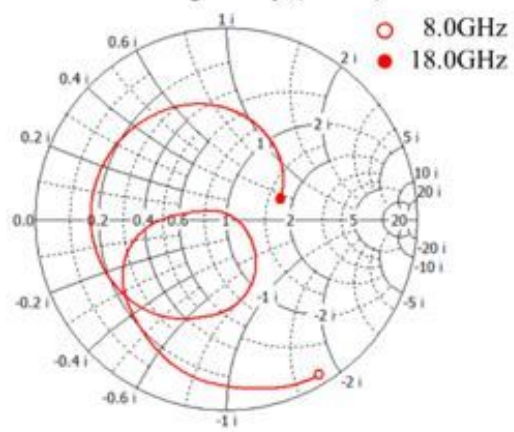

Simth chart

\section{Figure 5}

(a) The front and lateral view of the MRAC unit structure; (b) The $S$ parameter of the single metamaterial structure at various $\mathrm{f}$; (c) The simulated RL of the single Al2O3 coating and the MRAC with different t2s at 800 :; (d) Z of the single Al203 coating with a thickness of $1.5 \mathrm{~mm}$; (e) Z of the MRAC; (d) The smith chart. 


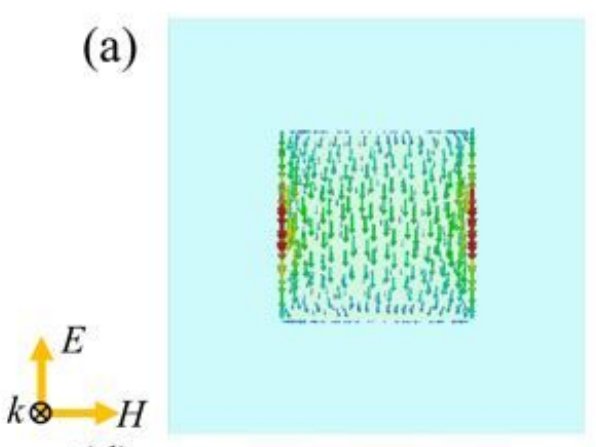

(d)

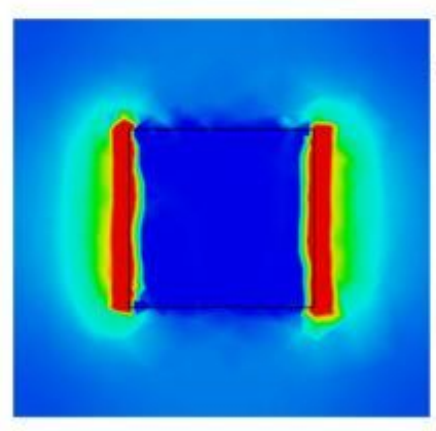

(b)

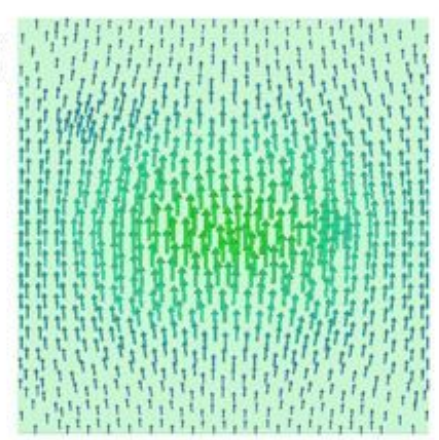

(e)

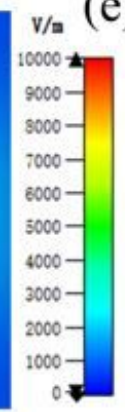

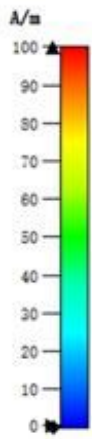

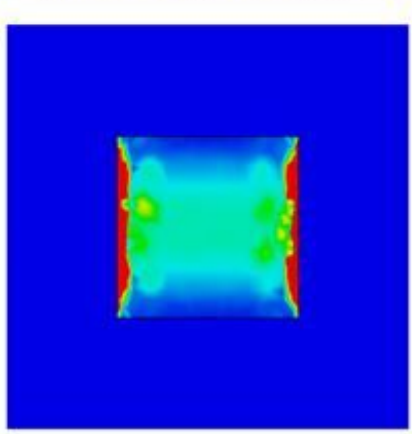

(c)

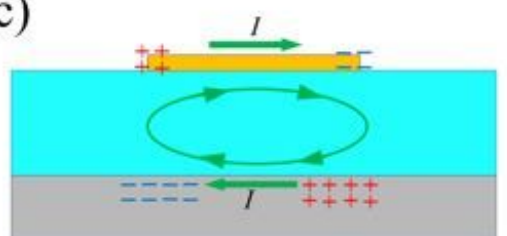

High-temperature conductive paste $\mathrm{Al}_{2} \mathrm{O}_{3}$ coating

Nickel-based superalloy (f)

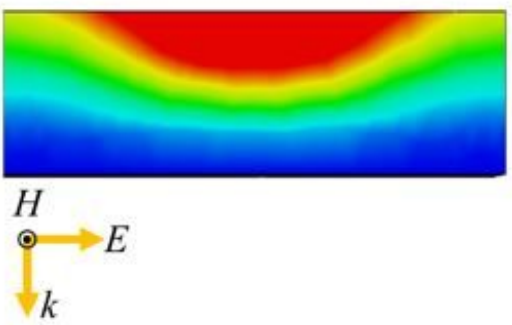

Figure 6

(a) The surface current in the metamaterial structure unit; (b) The reflective metal back plate current distribution; (c) Schematic of charge distribution for the MRAC and the circulating current; (d) The surface electric field of the MRAC; (e) The surface energy loss of MRAC; (f) The energy loss of a section.

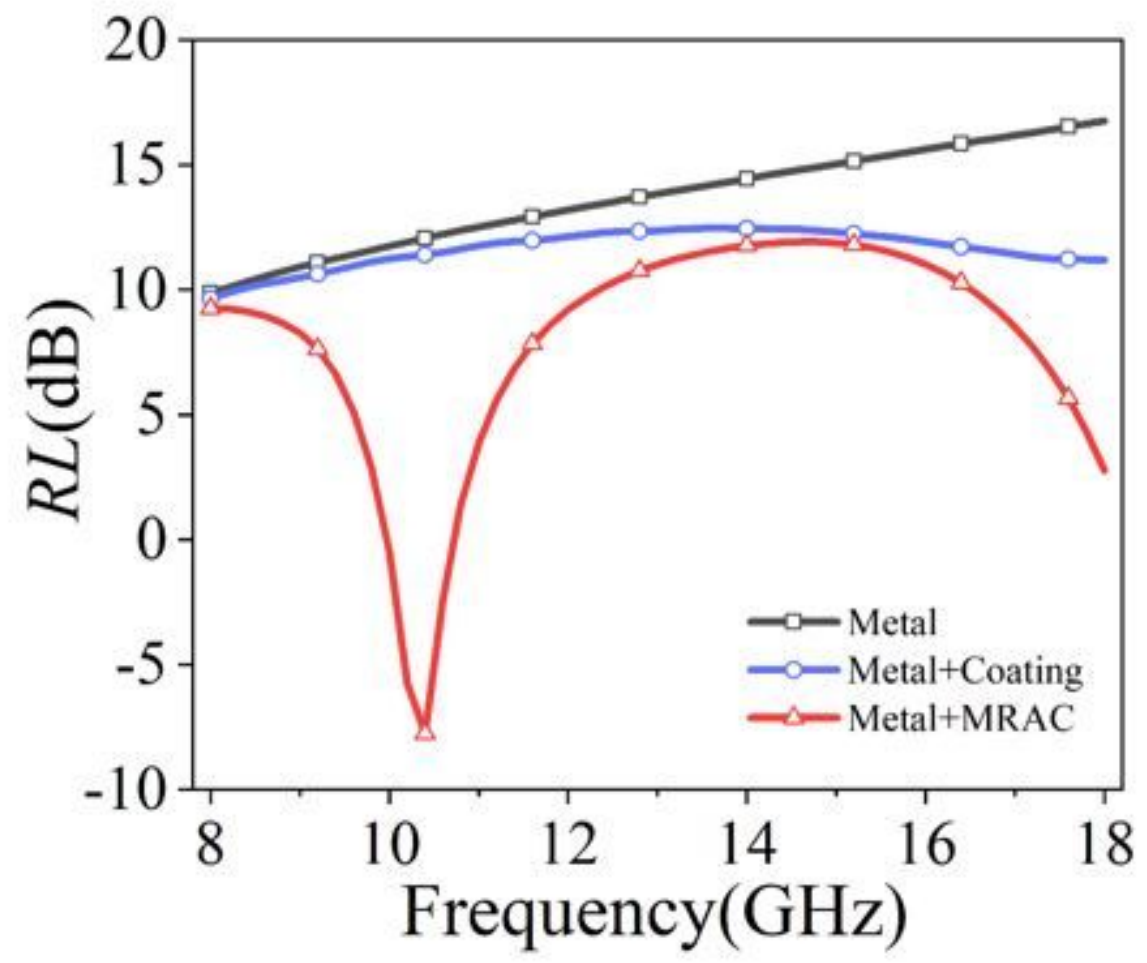


Figure 7

The simulated high temperature RCS spectra of the single Al2O3 coating and the MRAC.

(a)

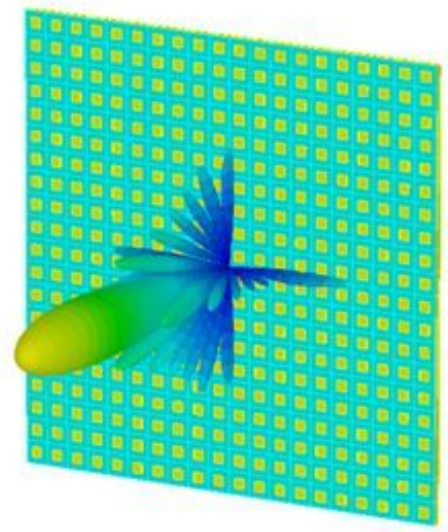

(d)

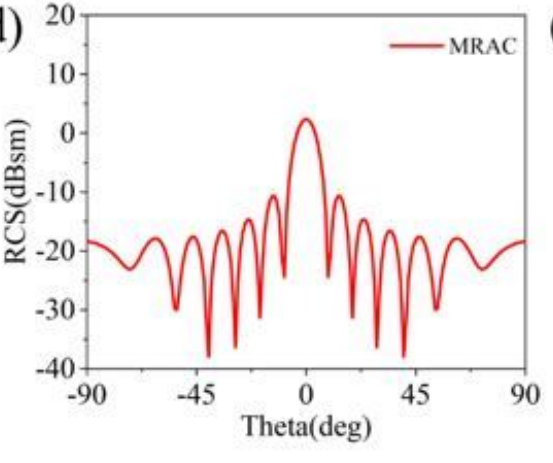

(b)

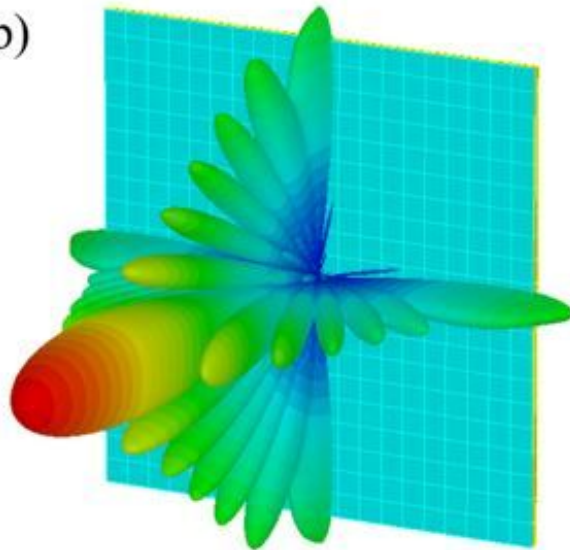

(e)

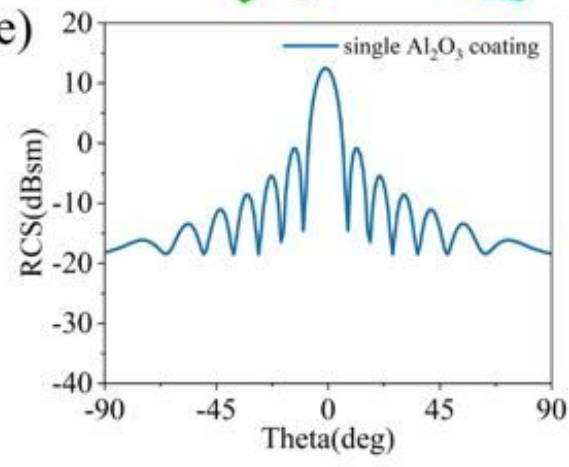

(c)

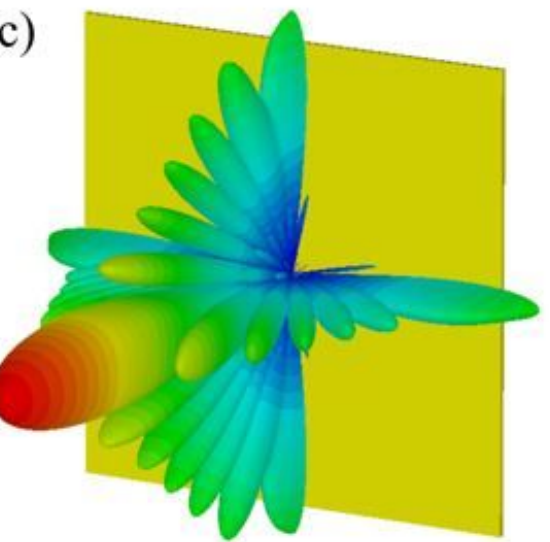

(f)

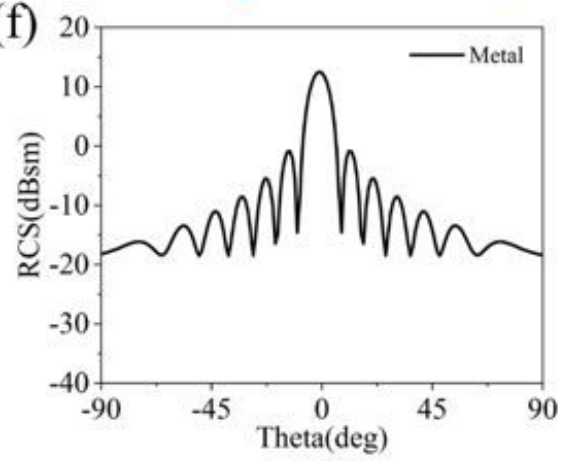

Figure 8

(a)(b)(c) The far field three-dimensional scattering patterns of MRAC, the single coating and the metal plate, respectively; (d)(e)(f) Their RCS in planes of Phi $=0^{\circ}$. 
(a)

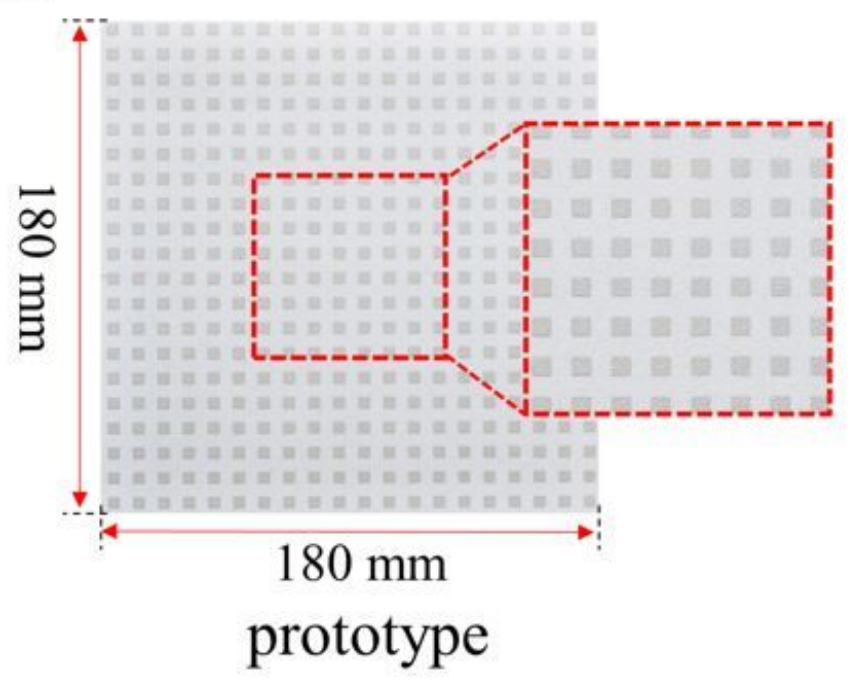

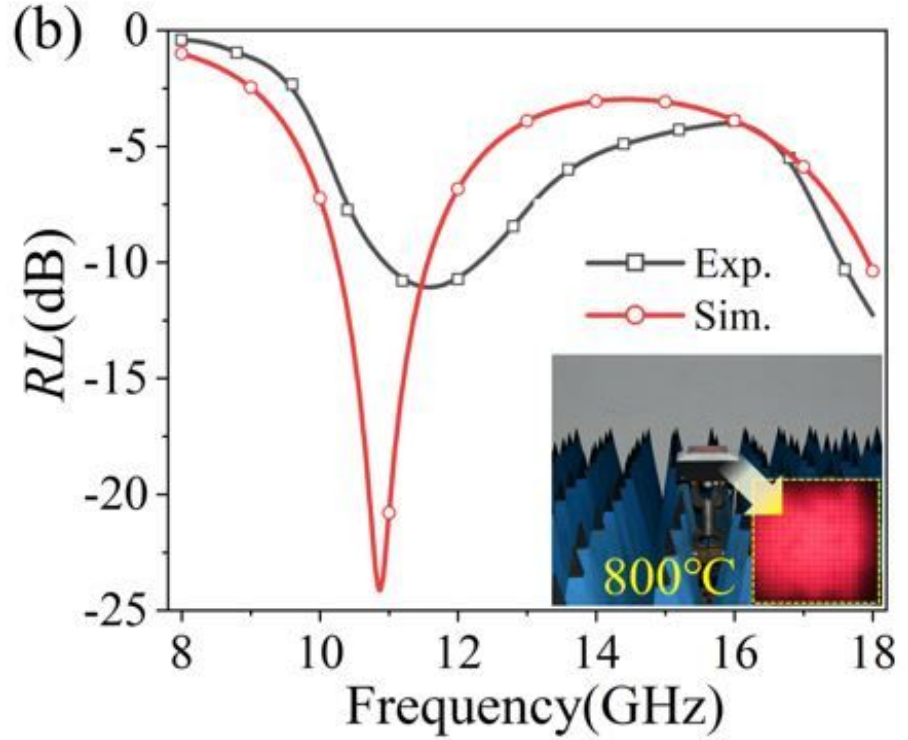

Figure 9

(a) The produced prototype of the MRAC; (b) A comparison between the experimental and simulated results. 